\title{
Estratigrafía constructiva y lesiones patológicas. Diacronía y coexistencia de materiales en la arquitectura del centro histórico de Cuenca (Ecuador)
}

\section{Constructive stratigraphy and pathological damages. The materials diachrony and coexistence in the architecture of the historical center of Cuenca (Ecuador)}

\author{
María del Cisne Aguirre Ullauri ${ }^{1}$, Amaranta Andreina Cortés Aguirre², Gema Mariela Zamora Cedeño³ \\ Universidad Politécnica de Madrid. Universidad Católica de Cuenca.
}

\begin{abstract}
RESUMEN
En el presente artículo se estudia el comportamiento de acción y reacción de catorce materiales de las fachadas de treinta y cinco edificios patrimoniales del centro histórico de Cuenca (Ecuador) y los factores del ecosistema a través de la lectura estratigráfica. Se busca identificar los actos constructivos o destructivos que definen el proceso histórico de su condición patrimonial y los estados de conservación determinantes para la intervención contemporánea. Entre los factores de impacto destacan las acciones físicas $(39,11 \%)$, mecánicas $(30,26 \%)$ y antrópicas $(21,03 \%)$, así como la sinergia entre estas y el deterioro de la calidad ambiental como catalizadores de procesos patológicos en materiales especialmente sensibles. Este aporte permite, por un lado, proyectar acciones primarias de intervención enmarcadas en la limpieza y mantenimiento como preámbulo a las de mayor envergadura, ya sea sustitución, demolición, restitución, entre otras; y, por otro lado, ensayar la herramienta metodológica como recurso crítico de análisis arquitectónico y superar así métodos de estudios más tradicionalistas.
\end{abstract}

Palabras clave: estrategia de intervención; estratigrafía muraria; lesiones patológicas; materiales históricos.

\begin{abstract}
This article studies the action-reaction behaviors of fourteen façade construction materials from thirtyfive heritage buildings in the $h$ istoric center of Cuenca-Ecuador, a nd the features of the e cosystem through stratigraphic reading. The objective of this article is to identify the constructive or destructive actions that define the historical process of the buildings' patrimonial condition as well as the determining states of conservation for contemporary intervention. The leading impact factors are physical $(39,11 \%)$, mechanical $(30,26 \%)$, and anthropic $(21,03 \%)$ actions, the synergy among them, and the deterioration of environmental quality as a catalyst of pathological processes, particularly in delicate materials. First, this contribution allows planning of primary intervention actions, primarily cleaning and maintenance, as a prelude to more important actions such as substitution, demolition, restitution, among others. Second, it also allows testing the methodological tool as a critical resource for architectural analysis to overcome more traditionalist study methods.
\end{abstract}

Key words: intervention strategy; wall stratigraphy; pathological damages; historical construction materials.

Recibido: 12-05-2019. Aceptado: 14-10-2019. Publicado online: 17-03

Cómo citar este artículo / Citation

Aguirre Ullauri, M. C., Cortés Aguirre, A. A. y Zamora Cedeño, G. M. 2020: "Estratigrafía constructiva y lesiones patológicas. Diacronía y coexistencia de materiales en la arquitectura del centro histórico de Cuenca (Ecuador)", Arqueología de la Arquitectura, 17: e093. https://doi.org/10.3989/arq. arqt.2020.002

Copyright: (c) CSIC, 2020. ( ) UPV/EHU Press, 2020. Este es un artículo de acceso abierto distribuido bajo los términos de la licencia de uso y distribución Creative Commons Reconocimiento 4.0 Internacional (CC BY 4.0).

cisne2222@hotmail.com / maguirreu@ucacue.edu.ec / ORCID iD: https://orcid.org/0000-0002-3179-7839

amarantha25@outlook.es / aacortesa02@est.ucacue.edu.ec / ORCID iD: https://orcid.org/0000-0001-7183-1678

gmzamorac.78@hotmail.com / gmzamorac39@est.ucacue.edu.ec / ORCID iD: https://orcid.org/0000-0002-9422-7526 


\section{INTRODUCCIÓN}

Estudiar, reflexionar o debatir sobre las particularidades arquitectónicas de la ciudad de Cuenca asociadas a su estatus de Patrimonio Histórico de la Humanidad -su centro histórico y su paisaje urbano- supone incorporar el aporte de diferentes disciplinas, de distintos saberes. En este sentido, la relación arquitectura/arqueología ${ }^{4}$ adquiere un valor sustancial en una ciudad en la que resulta sumamente relevante el peso histórico, cuyo testimonio se encuentra en las huellas de la ciudad cañariinca de Tumipamba o Tomebamba o en los diversos espacios públicos de la traza castellana. Pero esta relación no siempre se ha acogido de tal modo que estudios sobre la cultura material de la ciudad se han realizado al margen de la categoría de documento histórico de sus elementos. Esto ha dado lugar a que las propuestas sobrevenidas, al carecer de un estudio de la dimensión histórico-constructiva, no alcancen a comprender los contextos sociales y productivos históricos y contemporáneos en los cuales se germina esta cultura material, ni se contemple la interacción que se desencadena frente a las condiciones del ecosistema ${ }^{5}$, como recurso para su definición técnica que permita no solo enunciar un evento ruinoso del pasado sino describir el mecanismo de dicha situación e identificarlo como un hecho y proceso del presente.

Este estudio pretende superar esa carencia. Se plantea como objetivo analizar a los materiales de construcción del centro histórico de la ciudad para efectuar dictámenes patológicos y conocer su relación con el ecosistema. El estudio considera que el análisis estratigráfico, que permite la interacción arqueología/

\footnotetext{
4 El análisis de la relación desde los procesos conjuntos en la arquitectura del centro histórico de Cuenca fue desarrollado a partir de los Informes de Prospección de la extinta Unidad de Arqueología Urbana en el periodo 2008-2012.

5 Esta categoría se introduce como variable orientadora de la investigación. Considera para su aplicación teórica y práctica que, un ecosistema como sistema o estructura integrada se conforma de variables de interacción (Armenteras et al. 2016) en diferentes niveles. Como parte de la naturaleza las físicas incluyen desde el clima, la topografía hasta al hombre y sus actividades - productivas y destructivas-; a su vez como connotación histórica, el ecosistema incluye las singularidades culturales del sitio, el efecto acumulado de las prácticas colectivas y los comportamientos con las variables de la naturaleza. Así, se colige que, superando su definición conceptual más básica, el ecosistema en el caso de las ciudades históricas, productos diacrónicos y dinámicos incluye todas las variables del medio físico y las dimensiones de su identidad cultural. Resulta importante en este sentido la aproximación disciplinar del concepto de ecosistema propuesto por Armenteras et al. (2016), y su articulación a categorías como la de paisaje urbano histórico propuesto por la UNESCO, también como un producto histórico de la construcción teórica del patrimonio.
}

arquitectura, puede ofrecer aportes de interés por actuar como un recurso de análisis técnico e incluso posicionarse como un estudio previo a la intervención arquitectónica en el área urbana (Azkarate Garai-Olaun 2002). De esta manera, se podrá definir el comportamiento patológico y utilizarlo como recurso analítico de cómo se piensan e interactúan las sociedades actuales (Quirós Castillo 2002).

De forma concreta, el estudio toma como objetos de estudio catorce materiales localizados en treinta y cinco edificios del centro histórico de Cuenca. Su finalidad, por un lado, es abordar la relación entre ambiente ${ }^{6}$ y materiales de construcción, para lo cual se aplican las leyes estratigráficas, $\mathrm{y}$, por otro, determinar las posibles relaciones de afinidad o deterioro que el ambiente y la coexistencia física determinan. El texto inicia planteando las evidentes transformaciones urbanas de la ciudad y el peso del material de la construcción en su definición; luego explica la aplicación del método estratigráfico con orientación histórico constructiva y patológica, que permite comprender las vicisitudes a las que se exponen los materiales representativos de las fachadas. Y, en última instancia cuestiona las actuaciones contemporáneas que se admiten en dichos materiales, al tiempo que define ciertas estrategias de intervención que permitan actuar sin resquebrajar la relación con el paisaje urbano histórico.

\section{TRANSFORMACIONES VISIBLES: ARQUITECTURA E IMAGEN URBANA}

El proceso de urbanización y modernización de Cuenca ha estado condicionado por hitos sociales, culturales y económicos importantes a lo largo de su historia. Entre otros se destacan la transición entre la Independencia y Gran Colombia -entre 1820 y $1830-$, la bonanza derivada de la exportación de cascarilla y paja toquilla, la implantación del Neoclásico Francés como forma de modernización y la producción intelectual derivada de la vinculación al mercado mundial -entre 1890 y1940-, o la inserción de los instrumentos técnicos de administración

\footnotetext{
Esta categoría en sinergia con la de ecosistema considera que las variables del medio físico definen unidades territoriales cuyas condiciones e interacciones conforman ciclos históricos o temporales. En el caso de una ciudad histórica el ecosistema puede conformarse por varios ambientes, de los cuales las evidencias físicas, en la arquitectura por ejemplo, están condicionadas tanto al propio comportamiento como a connotaciones temporales. Así, el ambiente urbano incluye las variables del medio físico y las interacciones de uso y ocupación humana, que el ambiente natural las podría incluso considerar irrelevantes.
} 
y planificación urbana a partir de 1950. Este itinerario ha marcado cambios irreversibles en la ciudad que fue creciendo más allá de los límites de la terraza intermedia en la cual se había fundado, hasta acomodarse en las inmediatas para establecer y ratificar vínculos estrechos de larga duración con el resto del territorio, si bien en ese camino se han sobrepasado las nociones de uso racional del suelo y se ha afectado el equilibrio ser humano/paisaje. Un ejemplo de estas conexiones son los barrios artesanales, que nacieron implantados en sectores estratégicos del centro fundacional y tejieron redes de trabajo, intercambio y producción con la ruralidad, hoy periferia (Aguirre Ullauri, Sanz Arauz y Vela Cossío 2018). De ellos sobreviven escasas actividades, aunque su origen se mantiene con especial atención en el imaginario ciudadano ${ }^{7}$.

La arquitectura es uno de los componentes que más evidencian el cambio en la fisonomía de Cuenca (Jaramillo et al. 2004), y con ella, uno de los aspectos que visibiliza esas transformaciones es la explotación y aprovechamiento de recursos materiales asociados a la construcción y a la decoración, que han dado forma y sentido a las dinámicas temporales con el entorno. En donde más se aprecia esa evolución es en el núcleo fundacional, el centro histórico, porque en dicho espacio recae históricamente la concentración de actividades productivas, recreativas, habitacionales, administrativas y políticas. Es por eso que esta investigación toma como eje de análisis la fachada de las edificaciones patrimoniales en él emplazadas. A grandes rasgos, se establece que estos elementos arquitectónicos han sido concomitantes con los diversos periodos históricos por los que ha atravesado la ciudad. Así, en el periodo prehispánico proto-cañari, cañari e inca (hasta mediados del siglo XV) los materiales constructivos incluyeron a la madera, tierra y piedra. Durante la colonia y hasta 1830 se insertaron progresivamente los cerámicos, metales y pétreos decorativos; seguidamente $\mathrm{y}$ hasta mediados del siglo XX, tomaron representatividad los metales decorativos, revestimientos pictóricos y semejantes. Entre la década de 1970 e inicios del siglo XXI la utilización de materiales, a excepción de la tierra, se mantiene, más no la forma constructiva (González et al. 1980; Consulplan 1982; Gómez et al. 1986; León, Luna y Sigüencia 1997; Espinoza y Calle 2002; Moyano y Rivera 2002; Abad y Tommerbakk 2009; Caldas y Sigcha 2017).

\footnotetext{
7 El barrio de San Sebastián, uno de los más antiguos de la ciudad, da cuenta de la relevancia del componente socio-cultural asociado a la concepción, producción y transformación arquitectónica de la urbe (GAD de Cuenca 2018).
}

Una segunda forma de apreciar la transformación de la urbe y el crecimiento urbano es contemplar los cambios del paisaje, habitantes y recursos disponibles. Buena parte de la flora local debió ser depredada para ser usada en los múltiples proyectos de edificación de la urbe castellana y conforme el aumento demográfico lo requirió. Paralelo a ello se produjo la inserción de especies arbóreas como el eucalipto y el pino, materiales que progresivamente alcanzaron protagonismo, aunque ello no impidió la tala de especies endémicas. En cualquier caso, ese ecosistema secuencialmente se adaptó por medio de la versatilidad propia y adquirida del medio físico y el ser humano, en un proceso permanente de desequilibrios a nivel de biotopo y biocenosis.

En 1999 el centro histórico de la ciudad fue proclamado como Patrimonio Cultural de la Humanidad. El expediente de la declaratoria, al tiempo que destacó sus particularidades, reconoció también parte de las perturbaciones y desequilibrios históricos; la contaminación ambiental, como el segmento de mayor atención para la conservación del patrimonio arquitectónico ${ }^{8}$. Con este antecedente, en la ciudad se ejecutaron diversas propuestas y planes para el monitoreo sistemático de la calidad de aire -como los informes que se reportan con periodicidad (acción conjunta entre la Corporación Municipal y Fundación Natura, EMOV-EP y el Instituto Estudios de Régimen Seccional del Ecuador - IERSE) no obstante, no se puede ignorar que los múltiples componentes del crecimiento urbano y los cambios devenidos han dejado huellas que muestran que, en algunos casos, han existido afectaciones irreparables a este lugar paradisíaco, casi idílico, en donde es posible vivir en interacción y armonía con la naturaleza (Cardoso 2017), Criterio V que sostuvo la designación de la ciudad como patrimonio histórico. Esta realidad ratifica la constante despreocupación global por la gestión del ecosistema, particularmente en el ámbito urbano (Vásconez 2000), hábitat de ser humano contemporáneo. Por consiguiente, entender las dinámicas del territorio y sus habitantes en torno a la ecología y la sustentabilidad, en este caso mediante la comprensión del uso que se hace del elemento natural para la construcción de los edificios del núcleo urbano, podría ofrecer escenarios de actuación eficaces en la planificación urbana, con nuevos datos que rebasan las estrategias de control instauradas.

\footnotetext{
8 A nivel local son aportes valiosos al respecto los trabajos de Achig et al. (2016); Cardoso (2012) y De Jongh et al. (2009). A excepción del primero, que articula valores, riesgos y vulnerabilidades, las investigaciones se centran en la identificación y tipificación de lesiones.
} 


\section{LA LECTURA MURARIA: HERRAMIENTA METODOLÓGICA Y RECURSO DE PROBLEMATIZACIÓN}

La lectura estratigráfica muraria adapta los principios estratigráficos del ámbito arqueológico y geológico tradicional, con el fin de describir el proceso histórico que describe la condición actual de la arquitectura. Desde el segmento menos explorado pone de relieve la relación de los materiales y su interacción con el ambiente, es decir, entiende a la construcción como producto de agentes naturales, la acción antrópica consciente y voluntaria (Rolón 2013), capaz de incidir en la definición de las dimensiones físicas. Dado el impacto de los resultados que provee, se ha posicionado en el contexto internacional con reiterada solvencia, y se ha convertido en una herramienta sustancial de la arqueología de la arquitectura moderna, pero su conocimiento y aplicación como recurso investigativo o de desarrollo técnico a nivel nacional todavía es mínimo, salvo pocas aplicaciones en las que se incluye, por ejemplo, el análisis del edificio de la ex cárcel de Guayaquil o el de la antigua Casa de Hacienda de Shuragpamba ${ }^{9}$. En su lugar, han tomado protagonismo la historiografía y los ejercicios de documentación arquitectónica.

Por su origen, la lectura estratigráfica apoya la comprensión de la cultura constructiva y socioeconómica del patrimonio, que se valora porque enriquece la historia de una ciudad y sus habitantes, y se proyecta como articuladora de las prácticas territoriales. Ciertamente, este aporte histórico ha sido reconocido tangencialmente en la Carta de Cracovia. Principios para la conservación y restauración del patrimonio construido (Rivera Blanco y Pérez Arroyo 2000), en la Carta Internacional para la Conservación de Ciudades Históricas y Áreas Urbanas Históricas (ICOMOS 1987) y en los Principios para el Análisis, Conservación y Restauración de las estructuras del Patrimonio Arquitectónico (ICOMOS 2003). Estos y otros documentos que buscan asegurar que el proceso de intervención constituya la restitución de la memoria colectiva y afirmar la conservación de valores materiales e inmateriales para lo cual consideran necesario conocer la biografia del edificio y entender las soluciones constructivas pretéritas para consolidar

\footnotetext{
9 En el estudio del Convento de San Francisco (Quito), el componente de las prospecciones a nivel de subsuelo, es entendido erróneamente como un ejercicio de Arqueología de la Arquitectura, si bien se parte de la premisa del rescate de la vida a partir de los materiales constructivos. Para ampliar el tema, consultar Mercé Gandía y Gallegos Arias (2011).
}

decisiones presentes, prácticas posibles desde la dimensión estratigráfica.

Aplicar esta visión analítica de la arquitectura histórica y la forma de trabajar con visión proyectual y conservacionista supone, en primer lugar, superar binomios historiografía/proyecto y proyecto/obra que han predominado en los estudios en torno al patrimonio urbano y arquitectónico de Cuenca ${ }^{10}$. En segundo lugar, disminuir la pérdida de información arquitectónica, priorizar las acciones de conservación e incluso evaluar la noción destructiva de ciertas intervenciones efectuadas (Fortea Luna y Garcés Desmaison 2011), muchas de ellas celebradas más que cuestionadas. Y, finalmente dado que se pretende analizar fachadas del centro histórico de Cuenca, el método permitirá ampliar el conocimiento sobre los materiales que definen las técnicas constructivas de los edificios (en los que además se reconocen estilos y periodos), la variación de los factores del ecosistema y el comportamiento ciudadano, de manera conjunta. Esta interacción dará cuenta de semejanzas y diferencias en los actos constructivos, factores destructivos e intervenciones que informan más allá del estado físico de conservación del bien.

Al estudiar de esta manera los elementos -hasta ahora entendidos de manera aislada- según Ching (citado por Blanco-Rotea 2017), es posible ratificar a la arquitectura como un tipo de lenguaje que da cuenta de las formas en que las sociedades expresan su forma de habitar y sentir el mundo, se convierte en una expresión de la cultura hecha objeto. En este sentido, Jamieson (2003) apuntó que a través de la arqueología de patio trasero era posible aprehender la dualidad de las relaciones espaciales y las estructuras de poder que rodean a una ciudad como Cuenca. Con este antecedente teórico, la revisión de los edificios públicos y privados que conforman el centro histórico permitirá conocer un segmento desconocido aún de vida y de convivencia

\footnotetext{
De acuerdo con el documento Contenido básico de anteproyectos según categoría del inmueble, se conformaron dos niveles de aproximación: estado actual y propuesta. En el primer caso, se incluyó la documentación arquitectónica de tipo planimétrica, levantamiento fotográfico, detalles constructivos, reseña o estudio histórico del bien conforme los Términos de referencia para la elaboración de estudios históricos, análisis crítico histórico de la edificación, registro documental y diagnóstico de pintura mural y otros bienes muebles, más el informe de prospección arqueológica aprobado. A nivel de propuesta el alcance se mantiene en la documentación arquitectónica, e incluye especificaciones técnicas, estudio de color y memoria descriptiva. En el segmento de bienes públicos y sobre el material disponible en el Sistema Nacional de Contratación Pública, entre 2008 y 2017, el panorama se complementa con estudios ingenieriles y de señalética (Aguirre Ullauri y Sanz Arauz 2017).
} 
ciudadana, la que ocurre al margen del eje elitista, ampliamente relevado por la historiografía tradicional (Benedet 2012), esos espacios que conforman la ciudad oculta y sus traumas vividos (Idrovo 2008). Ciertamente, como arguyó Idrovo, la arquitectura cuencana deja entrever las huellas físicas del proceso histórico, que trascienden la mera deposición en el subsuelo y se hacen visibles en los muros.

Efectuar un análisis semejante implica, en el terreno de la práctica, una transformación de la gestión administrativa cotidiana y del desempeño del profesional independiente, así como el reconocimiento de la participación de la población, en cuyas manos se encuentra la gestión inicial e integral del patrimonio. Una manera de evidenciarlo posiciona el retomar y revisar el inventario y catastro de inmuebles y sitios con valor arqueológico localizados en el centro histórico elaborado en 2008, que identifica 4843 inmuebles a nivel primario (Idrovo 2008: 21), frente a los 3287 bienes incluidos en el inventario patrimonial realizado en el 2009 como antesala de la Ordenanza para la Gestión y Conservación de las Áreas Históricas y Patrimoniales del cantón Cuenca promulgada en febrero de 2010. Por consiguiente, la reforma y articulación normativa es impostergable; el Reglamento de uso del color y materiales en las edificaciones del Centro Histórico de Cuenca del año 2000, el Contenido Básico de Anteproyectos según categoría ${ }^{11}$ del inmueble y los Términos de Referencia para la elaboración de estudios históricos, deberán exponer premisas y determina normas que sobrepasen la noción del estudio de forma, función y tecnología y avancen a los componentes significantes del edificio -y su lógica individual- sin dejar de lado el desarrollo de políticas de educación patrimonial. Como punto de partida puede situarse la práctica española y los vínculos europeos descrito por Blanco-Rotea (2017), para ratificar la necesidad de su implementación y las dificultades advertibles en el proceso (Caballero Zoreda 2002). De igual forma, el Plan Especial del Centro Histórico de Cuenca, en proceso permanente durante al menos la última década, supone el escenario operativo asociativo mediante la tecnificación de los mecanismos de intervención, apoya la conducción de procesos e intervenciones eficaces y, como señalan Vicente, Ferreira y Mendes da Silva (2015), influye directamente en la rehabilitación social de comunidades y en el incremento económico.

\footnotetext{
11 Se refiere a las seis categorías definidas, en orden descendente son; Valor Emergente -E-, Valor Arquitectónico A -VAR A-, Valor Arquitectónico B -VAR B-, Valor Ambiental -A-, Sin valor especial -SV- e Impacto Negativo $-\mathrm{N}-$.
}

\section{CICLOS PRODUCTIVOS: CONTEXTO Y EXPECTATIVA}

Como Vitoria-Gasteiz para García Gómez (2009: 76), Cuenca no es un fenómeno aislado; sincrónica y diacrónicamente depende del medio en el que evoluciona, entendiéndose por tal como un sistema termodinámico abierto en el que la arquitectura constituye un elemento que interactúa a través de redes con otros elementos materiales, técnica constructiva, estructuras simples y complejas, tejido urbano y contextos territoriales-. En dicha interacción la configuración de relaciones estratigráficas se hace visibles, desde acciones -antrópicas o naturales- de erosión, transporte, deposición y/o uso. La ciudad, por tanto, es la encarnación, local y singular de los flujos que no dejan de transformarla (FernándezGaliano 1991: 90) en diferentes niveles y alcances, y la arquitectura una forma tangible de sinterizarla.

En Cuenca, espacio físico irrepetible, el metabolismo asociado a los materiales de construcción como sustancias esenciales del tejido urbano y la arquitectura, expone vínculos socioeconómicos y desarrollo cultural previo al establecimiento del capitalismo. Las fuentes de aprovisionamiento implantados en el contexto periurbano y rural -actual y pretérito- experimentan etapas de depresión relevantes -que parten de la poblacionalcuya incidencia en la continuidad del proceso productivo no se ha cuantificado, so pena de las rupturas significativas. Al considerar el caso de Sinincay, el Tejar, o Racar como itinerarios de extracción, producción y manejo de los más significativos materiales -travertino, andesita, ladrillo, teja y otros- de Cuenca y no solo el centro histórico. Más allá de su identificación y contextualización, no existen estudios o análisis sistemáticos sobre ciclos, artefactos o capital humano (Fig. 1). Situaciones semejantes dibujan materiales como la cal y los artefactos de su producción, e incluso el propio escenario; Lazareto representó hasta hace poquísimos años su último reducto $^{12}$. Conexa se encuentra la situación de la madera, que proveniente en inicio de los bosques nativos, evidencia la mutilación del hábitat inmediato al centro histórico, y

\footnotetext{
12 Entre el año 2017 y 2018 se realizó el levantamiento arquitectónico de los hornos (3) que perviven en la zona. Estos presentan estados de conservación entre la ruina y potencialmente operativo, sin embargo, las limitaciones normativas de índole ambiental no vislumbran su reactivación. Dicha condición está dada por las significativas emisiones de $\mathrm{CO}_{2}$ propias del proceso artesanal de quemado y a la utilización de gran cantidad de madera. Se aspira a que en breve dicha investigación salga a la luz, más cuando también trastoca los vínculos de género, producción y arquitectura.
} 


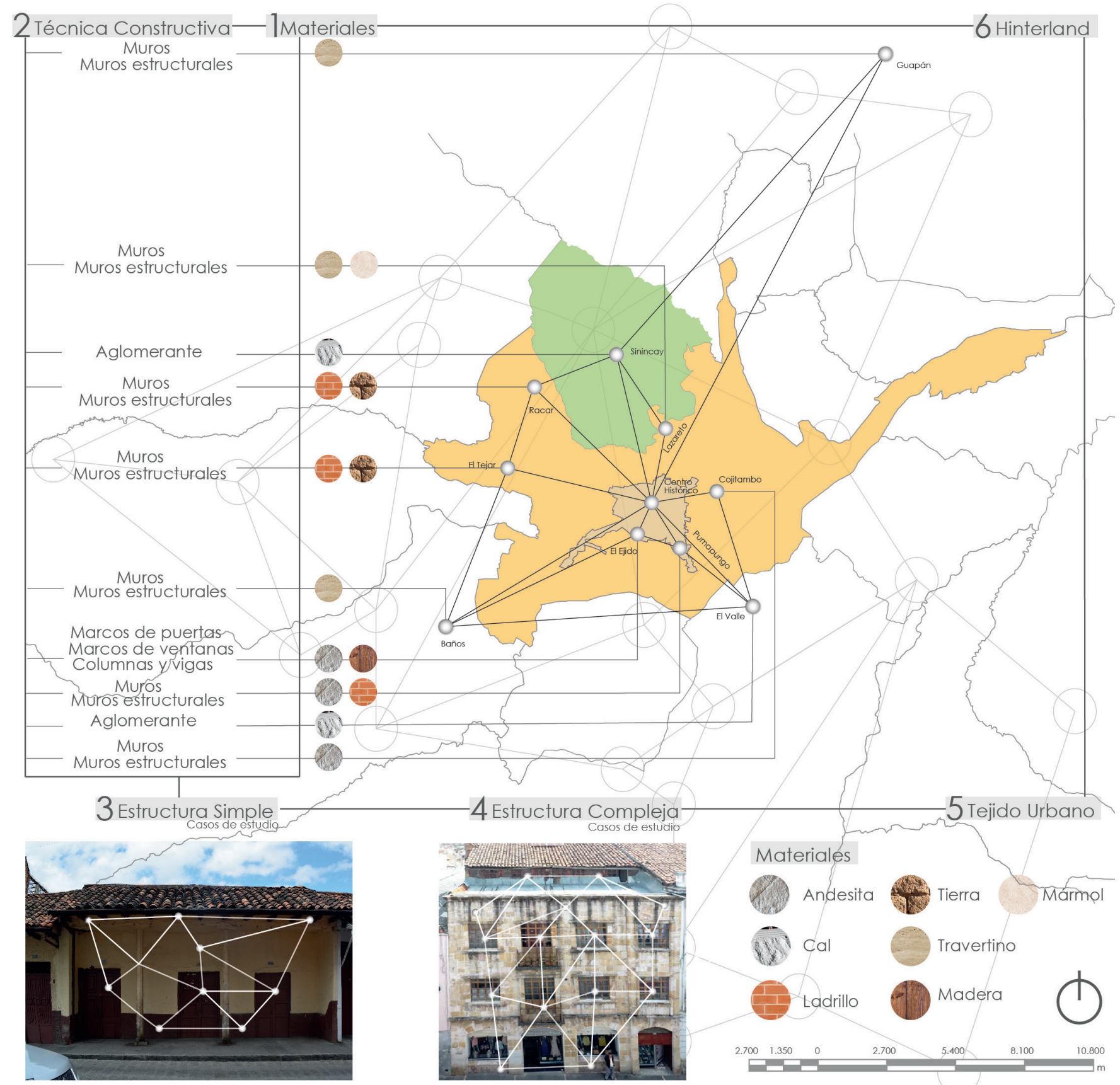

Figura 1. Cartografía de escalaridad concurrente, hinterland y patrón reticular según García Gómez (2009) aplicado al centro histórico de Cuenca. Elaboración: Amaranta Andreina Cortés 2019.

el irrespeto de la vocación natural (Mannoni 2006) y la cosmovisión prehispánica ${ }^{13}$ de su manejo.

\footnotetext{
13 Alulema Pichasaca (2018) desarrolla la relación del ser humano con la naturaleza mítica en el caso cañari. Describe la relación hacia el sumak kawsay desde los saberes de la medicina tradicional, etnobotánica, taxonomía de las plantas, la ritualidad y la intervención de los seres con poderes sobrenaturales. Concluye con la articulación de la sabiduría que profesan los yachakkuna y las madres de familia, las comadronas y otros personajes, en los diversos ciclos productivos con apoyo de la revisión histórica de la matriz agraria.
}

Por ello, la aproximación estratigráfica desde la lectura muraria supone un insumo integral de impulso investigativo capaz de reconocer la significancia holística de la arquitectura. Segmentos complementarios como la sucesión temporal y organización de la obra (Pizzo 2009), o la transformación de los paisajes -de inicio, trascurso y fin- vinculados resultan de interés y muestran la importancia desde el panorama romano tratado por Pizzo (2009), el mexicano según Álvarez 
Palma (2001) o la proyección del sevillano según Vargas Lorenzo (2013).

Con esta perspectiva, la visión ampliada hacia la definición de cultura arquitectónica, cultura constructiva y ecología cultural se posicionan en añadidura al reconocimiento de las múltiples dimensiones temporales y materiales contenidas en el producto arquitectónico actual. A partir de estas relaciones se orienta la posición del patrimonio arquitectónico como recurso histórico de desarrollo, cuyo análisis material desde la discusión crítica debe ser continuada, verificada y actualizada a medida que se estudien nuevos hallazgos (Mannoni 2005). No en vano Moreno Martín (2014) indica que la arquitectura es el punto donde convergen habilidades técnicas, posibilidades materiales e intereses ideológicos de la sociedad.

\section{MÉTODO}

\section{El punto de partida}

La Arqueología de la Arquitectura, más que una herramienta de análisis, es un corpus de información que hace que todos los elementos que se integran en él tengan un significado, no como entes independientes, sino como un todo (Vargas Lorenzo 2013: 2). Bajo esta premisa, se reconoce en la lectura estratigráfica muraria el medio para la decodificación el paramento frontal de edificios para articular su historia constructiva al estado de conservación según las condiciones del ecosistema del CHC.

De esta manera, no solo se pretende cotejar la narración histórica -vinculada a lo económico y socialposicionada sobre el uso de los materiales icónicos en la urbe. La mera aplicación procedimental tampoco resulta determinante. Los amplios aportes de Brogiolo, Parenti, Mannoni, Caballero, Azkarate y otros investigadores, contextualizan lo propio, en el más amplio sentido. Por tanto, la búsqueda y articulación de posibles recurrencias en el comportamiento de los materiales frente al medio a través de las huellas directamente visibles, supone el interés primero de la investigación.

\section{La aplicación}

Para efectuar el diagnóstico patológico de los materiales de valor histórico empleados en la arquitectura del centro histórico de Cuenca, el estudio emplea como herramienta metodológica la lectura estratigráfica muraria, para lo cual recurre a los aportes pioneros de Harris (1991), las adaptaciones de Caballero Zoreda (1995) y Blanco-Rotea (2003), así como a las innovaciones sobre lesiones patológicas y lectura estratigráfica ensayadas por Talaverano, Cámara y Murillo (2018). Además, se acude al registro arquitectónico (Ayán Vila 2003) para determinar el rol de los factores del ecosistema y el marco normativo vigente. De este modo, se defiende que la postura metodológica supone un universo de experiencias diversas en proceso de construcción y experimentación, enriquecido de forma constante con distintos enfoques (Azkarate Garai-Olaun 2013), cuyo potencial no explorado puede significar cambios sustanciales en el entendimiento de la arquitectura, la ciudad y la sociedad que las define.

Operativamente, la investigación considera como universo de estudio 35 fachadas de edificios patrimoniales del centro histórico de Cuenca ${ }^{14}$ cuya selección obedece a criterios de representatividad en la categorización patrimonial vigente, emplazamiento y vinculación al desarrollo histórico de la urbe y/o a sectores estratégicos como vías, barrios u otros (Fig. 2). En adelante se realiza: (1) documentación arquitectónica; (2) dictamen patológico inicial con aporte transversal de fichas arquitectónicas que incluyen la inspección organoléptica y de desarrollo geométrico de cada lesión; (3) evaluación de impacto ambiental ${ }^{15}$; (4) análisis histórico constructivo; (5) análisis patológico conforme a las leyes estratigráficas; y (6) propuesta básica de intervención.

La información inicial levantada en la ficha arquitectónica incluyó veinte materiales potenciales para ser estudiados, designados con base en la tradición constructiva local y la narración historiográfica posicionada. No se analizaron materiales como arenisca porque durante el levantamiento de campo no se logró identificar con claridad sus características. Tampoco se incorporaron materiales decorativos como azulejos, latón policromado, teja y carrizo, propios del nivel interior y de cubiertas. Se espera que futuras investigaciones puedan

\footnotetext{
14 Las fachadas fueron escogidas como objetos de estudio en el proyecto de investigación titulado Los materiales en el estudio histórico-constructivoambiental de los conjuntos históricos. El caso de Cuenca, vinculado a la IV Convocatoria de Proyectos de la Universidad Católica de Cuenca (Ecuador). El presente estudio forma parte de esa investigación, vinculada a la tesis doctoral de la primera autora.

15 El proceso metodológico aplicado puede ampliarse en Aguirre Ullauri et al. (2018a), mientras que los resultados pormenorizados en Aguirre Ullauri et al. (2018b).
} 


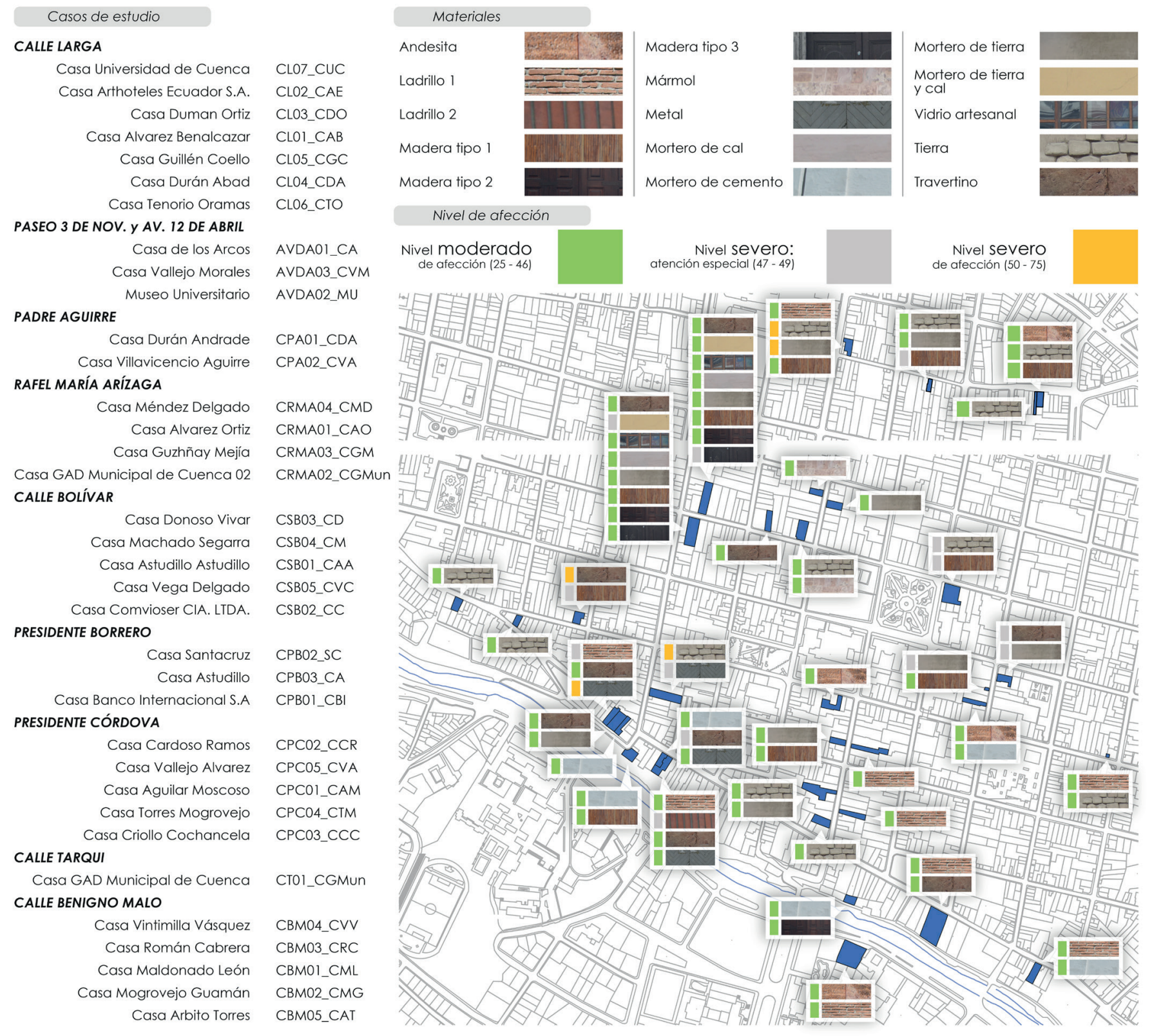

Figura 2. Cartografía de casos de estudio y evaluación ambiental. Elaboración: Gema Mariela Zamora 2019.

abordar estos elementos ya que están especialmente articulados a la tradición arquitectónica de la ciudad.

\section{RESULTADOS Y DISCUSIÓN}

De los veinte elementos potenciales de los que partió el estudio, el análisis se centró en catorce a los que clasificó de la siguiente forma: (a) pétreos (andesita, travertino y mármol), (b) metales (hierro forjado u otro), (c) ladrillo y tierra (tres tipos visualmente diferentes en el primer caso), (d) madera (tres tipos visualmente diferentes), (e) vidrio artesanal y (f) morteros (de tierra, cal, cemento y mixto). La afección sufrida por estos materiales se puede apreciar en la figura 3.

Se observa que al considerar variables como origen, vulnerabilidad potencial, ubicación, proximidad a sí mismo y a otros materiales, el nivel de deterioro del material puede ser significativamente mayor o menor. De ese modo, se aprecia que la madera, el champeado de cemento y el mortero de cal no revelan mayor deterioro por coexistencia consigo mismo, mientras que en el resto de casos, las lesiones que sufren dependen del origen de la materia prima, su composición o su reacción frente 


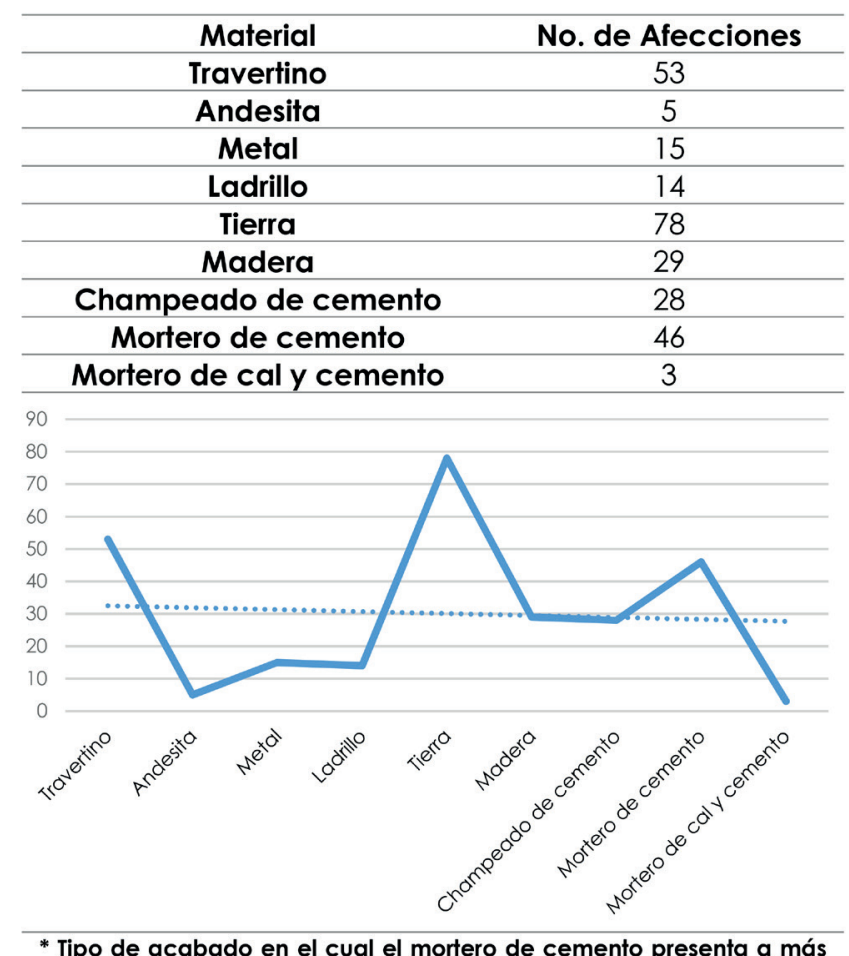

* Tipo de acabado en el cual el mortero de cemento presenta a más de árido fino, árido grueso de hasta $9 \mathrm{~mm}$.

Figura 3. Lesiones identificadas por material de estudio. Elaboración: Gema Mariela Zamora y María del Cisne Aguirre Ullauri 2019.

al medio (Fig. 4). Los resultados también demuestran que elementos arquitectónicos construidos con materiales similares, pero expuestos a variaciones del ambiente y diferentes condiciones de uso, extensión y relación de antero posterioridad, no exhiben igual nivel de deterioro o conservación.

\section{Materiales y diacronías}

Al no enmarcarse en la mera relación comparativa, la aproximación estratigráfica permite, como instrumento técnico, contextualizar en alguna medida el comportamiento de los materiales, reconociendo las singularidades de cada uno, si bien no definible en su integridad debido a la inexistencia de estudios de caracterización o estudios patológicos previos. Producto de esta contextualización se obtienen las siguientes particularidades:

\section{Pétreos}

Al ser materiales provenientes de formaciones rocosas, poseen características diversas y desiguales. Particularmente el travertino es uno de los más afectados (Aguirre
Ullauri, García Cordero y López León 2018). Se trata de una roca de origen sedimentario compuesta principalmente por carbonato de calcio (Taramasso 1943), puede tener color gris, amarillo, rosado y verde, y se localiza en el sector de Baños (Plan de Ordenamiento Territorial 2015), si bien otras fuentes lo ubican en la formación Yunguilla (Instituto Geográfico Militar -IGM- 1974). La amplia disponibilidad incentivó su uso en la renovación progresiva de la ciudad entre 1890 y 1940, como elemento decorativo y resistente. A nivel patológico la situación está definida descendentemente por relaciones constructivas o intervencionistas posteriores, anteriores y contemporáneas (Fig. 5) a independencia del factor de generación, están asociadas al contacto del material consigo mismo y con morteros y metal de manera predominante (Fig. 6), aun así, destacan las afecciones por factores físicos $(35,85 \%)$, mecánicos $(39,62 \%)$ y antrópicos $(24,53 \%)$, identificados en forma de desprendimiento y pintadas $(24,53 \%)$, humedad $(18,87 \%)$, fisuramiento $(15,09 \%)$, erosión $(9,43 \%)$, descamación $(5,66 \%)$ y suciedad por depósito $(1,89 \%)$.

En el caso de la andesita, sufre mayores afecciones por coexistencia temporal consigo misma, con los morteros, madera y metales - potencialmente hierro forjado(Fig. 6). En cuanto a las relaciones físicas advertibles, predominan aquellos de tipo apoyo, corte, adosamiento y superposición, los cuales demuestran que la posterioridad es el segmento temporal de mayor incidencia, seguido de la anterioridad y la coetaneidad (Fig. 5). Esta situación ha dado lugar a afecciones como la colonización por líquenes (40\%), humedad (20\%), suciedad por depósito (20\%) y reemplazo de material $(20 \%)$, de tal suerte que las afecciones físicas y biológicas (40\%) predominan frente a las antrópicas $(20 \%)$.

En consecuencia, la diversidad de lesiones expuestas y la diversidad de grado de la afección, entre severo y moderado (Fig. 2) evidencian la vulnerabilidad de los pétreos ante la sinergia y acumulación de procesos patológicos. La exposición constante a la intemperie, los cambios de temperatura, las vibraciones y vientos se convierten en factores altamente influyentes en un entorno de considerable contaminación como el caso del centro histórico de Cuenca (Orellana Samaniego, Sellers Walden y Martínez Gavilánez 2017). Igualmente, se aprecia la existencia de varios grupos de pétreos como las tobas, calcáreas, calizas y mármoles, de similares características visuales, aspecto físico exterior, por su origen y composición, lo que genera confusión en el momento de la identificación de otras particularidades. 

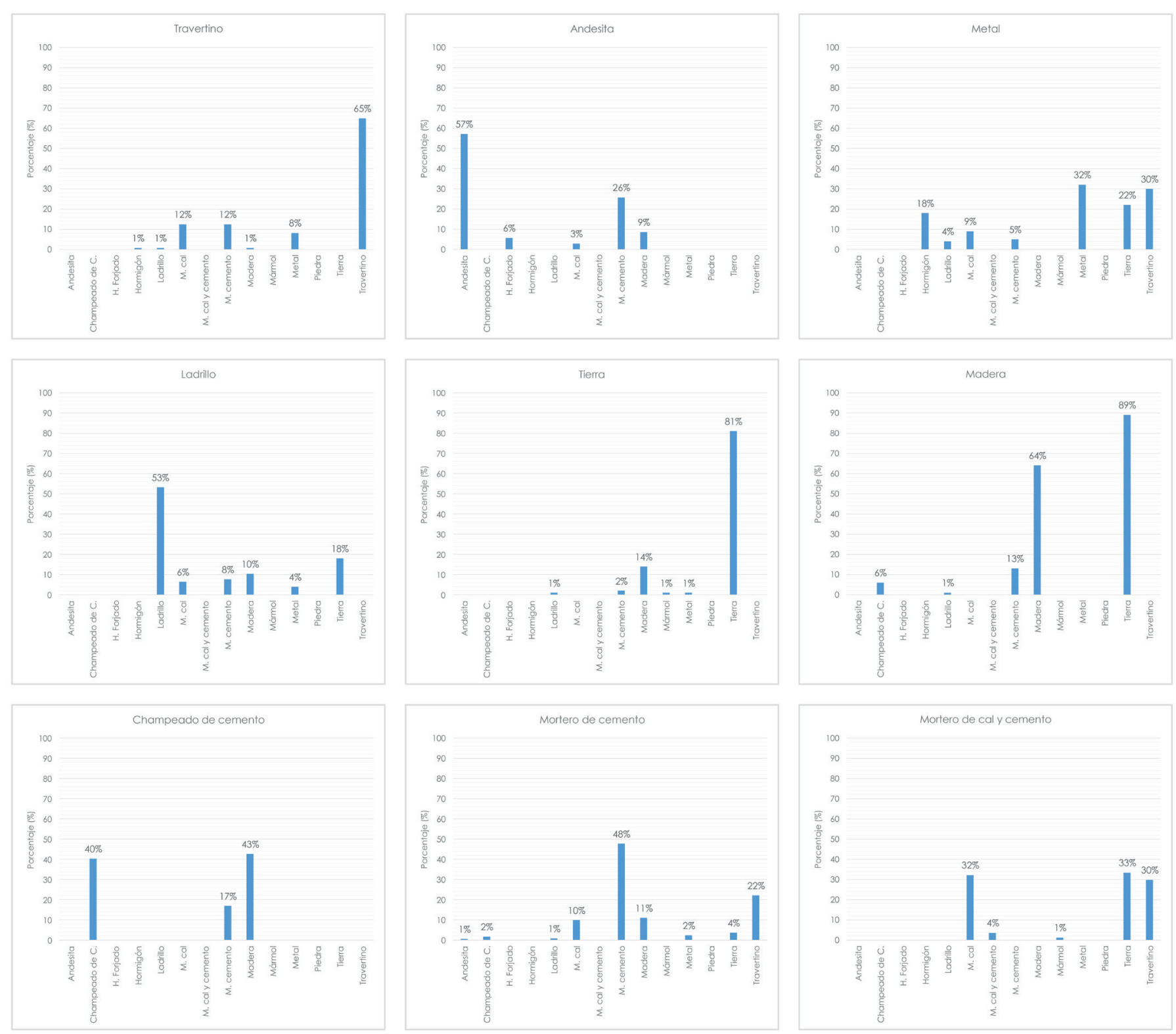

Figura 4. Mosaico estadístico sobre el comportamiento patológico entre los materiales de estudio. Elaboración: Gema Mariela Zamora 2019.

Por tanto, se puede afirmar que los pétreos utilizados, ya sea al inicio del proceso edificatorio o en posteriores intervenciones, son materiales cuyas características se desconocen a nivel particular, aunque presenten similitudes; por ejemplo, la diferencia entre tobas oscuras y travertino no es notoria a simple vista, tanto que no se suele apreciar las variaciones cromáticas en el travertino local; sin embargo, las propiedades químicas y origen de dichos materiales son completamente diferentes (Taramasso 1943) (Fig. 1). La inexistencia de estudios analíticos sobre los pétreos locales limita mayores aproximaciones que las expuestas, pero define un escenario propicio para la investigación.

\section{Metal}

Al estudiar este material se han considerado las estructuras de hierro fundido, forjado o semejante con presencia significativa en la arquitectura del área histórica analizada, aunque a simple vista sus rasgos diferenciadores no resulten tan perceptibles. En algunos casos, metales en general y el tradicional hierro forjado se tratan como uno solo ante la carencia de mayores referentes técnicos. A nivel patológico se aprecia que las mayores incidencias se han producido cuando el material coexiste consigo mismo, con tierra, travertino y hormigón, y que las incidencias son menores cuando 

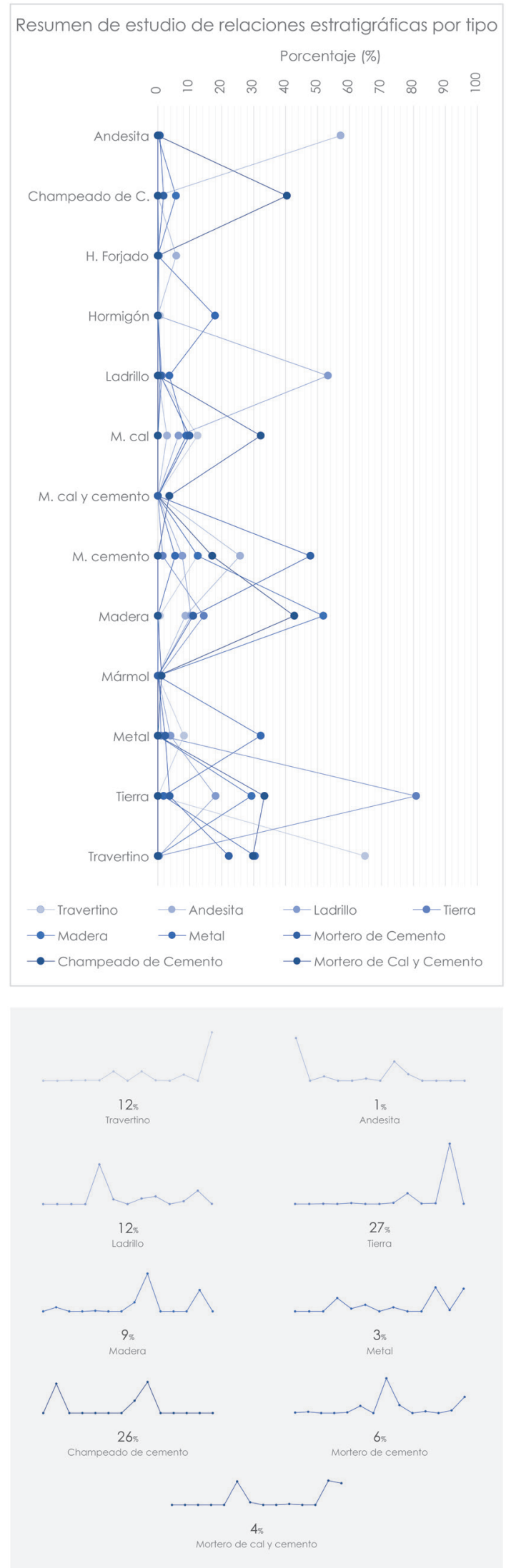

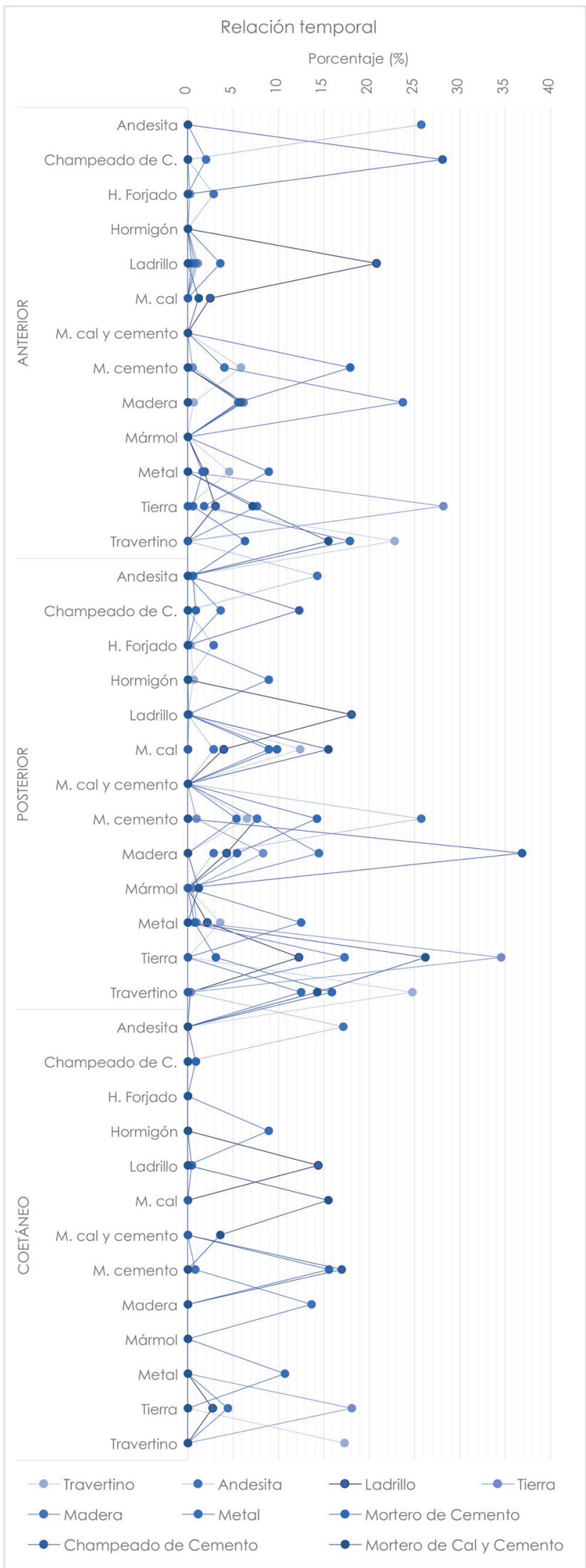

Figura 5. Relación estratigráfica y temporal acumulada de los materiales en análisis. Elaboración: Gema Mariela Zamora 2019. 

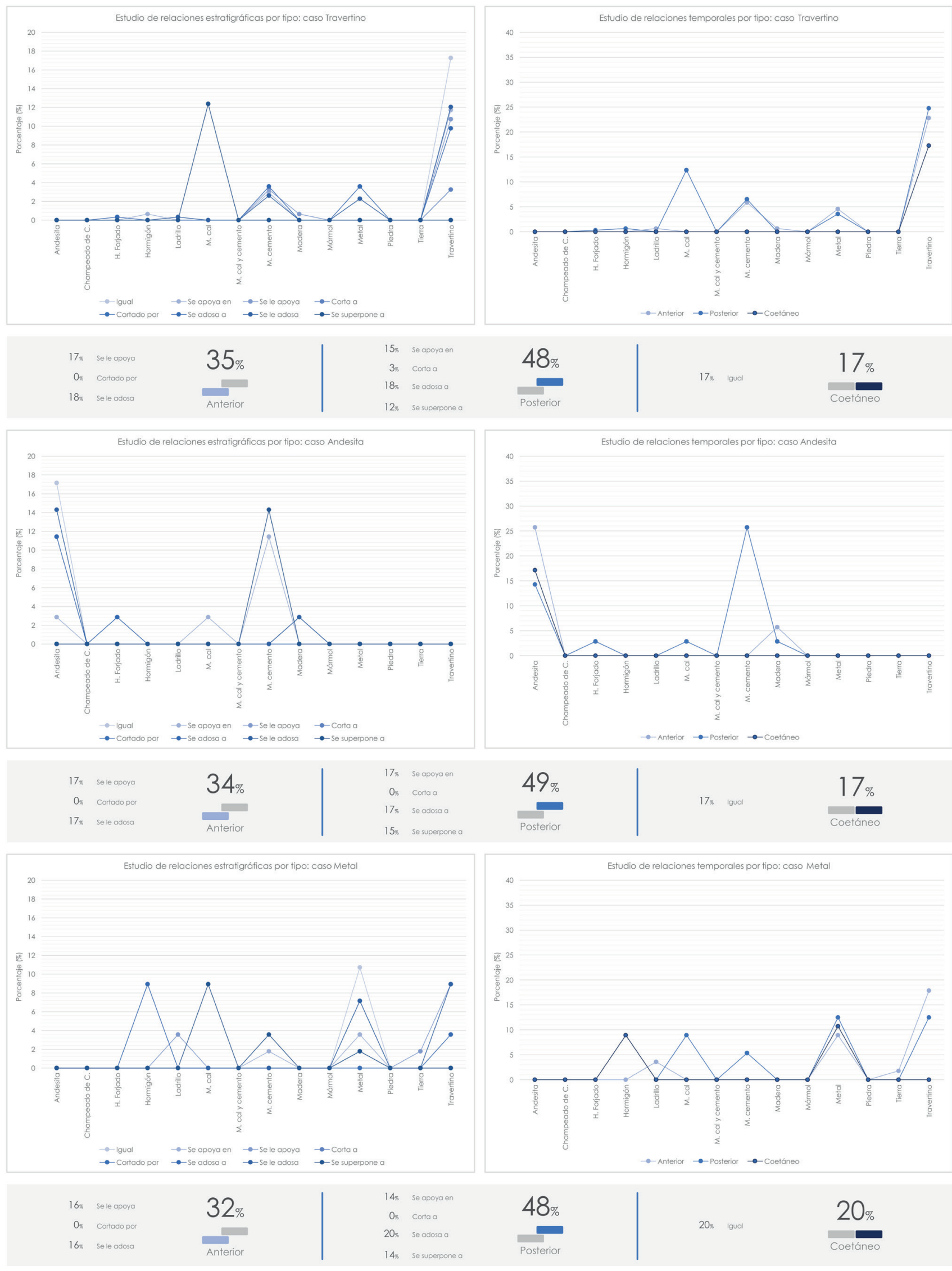

Figura 6. Relación estratigráfica y temporal de travertino, andesita y metal. Elaboración: Gema Mariela Zamora 2019. 
coexiste con el ladrillo y los morteros (Fig. 4). Las relaciones físicas de posterioridad contextualizan esta condición igual a lo que ocurría en el caso de los pétreos (Fig. 6). Así mismo se identificó que las lesiones físicas $(33,33 \%)$, biológicas $(26,67 \%)$, antrópicas (26,67\%) y químicas $(13,33 \%)$ definen el panorama patológico a través de humedad $(33,33 \%)$, pintadas $(26,67 \%)$ y oxidación $(13,33 \%)$.

Las lesiones se acentúan ante el alto índice de precipitaciones en la ciudad y ante la acción de agentes como la contaminación del aire y variaciones drásticas de humedad relativa, que desencadenan procesos permanentes de deterioro o activan temporalmente otros. Así mismo la presencia de metales estimula el deterioro de materiales cerámicos y pétreos preexistentes.

\section{Ladrillo y tierra}

Se consideran de manera general en la misma categoría de análisis, ya que por definición y naturaleza poseen características similares como plasticidad, permeabilidad, cohesión, estabilidad y cambios ostensivos al contacto con el agua. No se desconocen las variaciones significativas asociadas al quemado, que deberán considerarse como parte de un estudio complementario. La tradición constructiva de la ciudad muestra que ambos materiales se han venido empleando como materia prima en la construcción desde el periodo prehispánico. En el conjunto de objetos estudiados, el 21,74\% de las edificaciones utilizan sistemas asociados a la tierra, y el $13,04 \%$ al ladrillo (Fig. 7). Ciertamente, este proceso extendido de uso ha diversificado las formas de emplearlos en la construcción, tanto que sus formas y usos han definido la imagen y singularidad de la denominada arquitectura cuencana que, de la mano de ingenieros y arquitectos locales, busca de manera permanente recuperar prácticas constructivas. Pese a este valor histórico y técnico-constructivo, no se han desarrollado aún estudios cronotipológicos, mensiocronológicos o semejantes sobre ellos.

Estos materiales se ven afectados en mayor grado por coexistencia consigo mismos. En el caso de la tierra muestra incompatibilidades con la madera y, en menor proporción, con otros materiales; por su parte el ladrillo es afectado por la tierra, los morteros y los metales (Fig. 4). A pesar de estas diferencias, tanto ladrillo como tierra se han visto afectados por prácticas de naturaleza posterior, seguidos de las actuaciones anteriores y contemporáneas (Fig. 7).
En el caso de la tierra, su empleo en gran parte de los objetos de estudio se desprende del enorme valor cultural y social legado de generación en generación (Rodríguez et al. 2011) a los habitantes de la región (Fig. 1). No obstante, la acción de agentes intrínsecos, antrópicos, variaciones climáticas y el paso del tiempo lo convierten en uno de los materiales más afectados (Figs. 2 y 4). El estudio muestra lesiones mecánicas $(54,55 \%)$, físicas $(28,41 \%)$, antrópicas $(11,54 \%)$ y biológicas $(7,69 \%)$ a partir de desprendimientos $(41,03 \%)$, fisuramientos y grietas $(15,38 \%)$, pintadas $(11,54 \%)$, humedad $(7,69 \%)$, presencia de depósitos fecales y hongos $(3,85 \%)$, deformaciones $(1,28 \%)$. Por su parte, en el ladrillo se aprecian procesos de deterioro de tipo físico (85\%), mecánico y antrópico $(7,14$ $\%)$, identificables a partir de meteorización $(64,29 \%)$, humedad $(21,43 \%)$ y desprendimientos y pintadas $(7,14 \%)$.

\section{Madera}

Este material proviene de la diversidad de especies nativas o introducidas en la región; infortunadamente se carece de estudios sobre el tipo de madera empleada. De forma general y unificando los tipos de madera, se encuentra que los principales agentes patógenos de este elemento son la tierra, la misma madera y, en menor medida, otros factores asociados al cemento (Fig. 7). Las diversas afecciones que sufre están determinadas por las características higrométricas propias, así como por los ejercicios de apoyo, corte, superposición y adosamiento que experimenta (Fig. 5) y en menor escala por los del marco de anterioridad y coetaneidad. El estudio ha identificado que diacrónicamente el material se ve afectado por lesiones físicas $(34,48 \%)$, antrópicas $(24,14 \%)$, mecánicas $(20,69 \%)$, biológicas $(13,79 \%)$ y químicas $(6,90 \%)$, en forma de pintadas $(24,14 \%)$, descamación $(20,69 \%)$, pudrición $(13,79 \%)$, deformaciones $(10,34$ $\%)$, humedad, suciedad por depósito, desprendimiento y decoloración $(6,90 \%)$.

\section{Morteros}

Se analizó al mortero de cemento, chapeado de cemento, mortero de cal y cemento, y mortero de tierra. Los dos primeros se encuentran afectados sobre todo por sí mismos a través de relaciones físicas de naturaleza posterior, por las actividades de influencia anterior y finalmente por las coetáneas (Fig. 5). En el champeado 

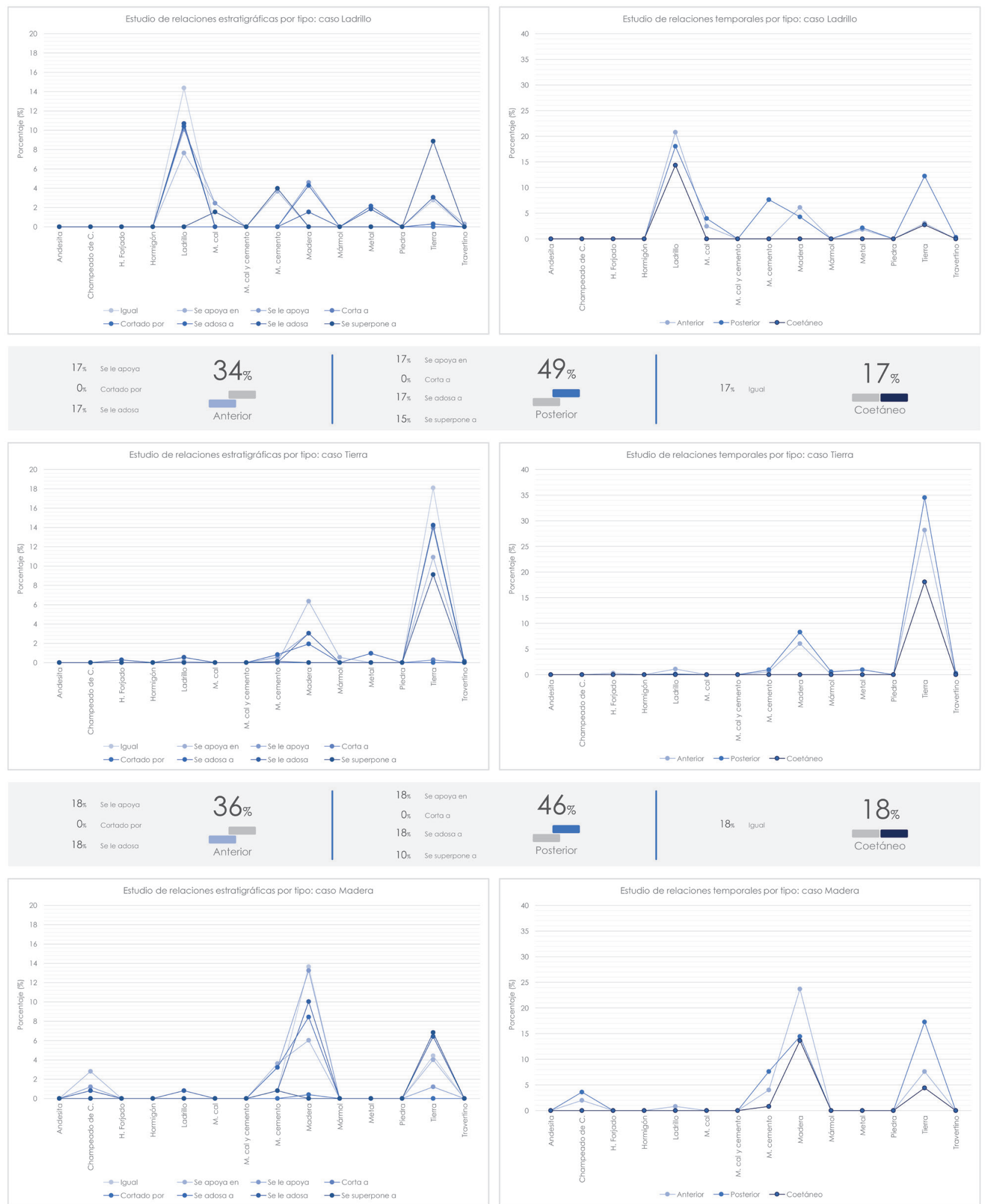
$19 \pi$ Sele opoya
0 Cortado por
$38 \%$
16: se apova
Os corta a
$43 \%$
198 loval
$\frac{19 \%}{\text { Coetóneo }}$

Figura 7. Relación estratigráfica y temporal de ladrillo, tierra y madera. Elaboración: Gema Mariela Zamora 2019. 
de cemento como síntomas de las interacciones se evidencian lesiones antrópicas de tipo pintadas $(53,57$ $\%)$, químicas en forma de eflorescencias $(21,43 \%)$ y las mecánicas y físicas $(17,86 \%$ y 7,14 \%) a partir de desprendimientos y meteorización. Por su parte el mortero de cemento presenta lesiones predominantemente físicas $(63,04 \%)$, mecánicas $(21,74 \%)$ y antrópicas $(15,22 \%)$, descriptibles a partir de humedad, descascaramiento $(36,98 \%)$, desprendimiento $(21,74 \%)$, pintadas $(15,22$ $\%)$ y suciedad (2,17\%). Y en el mortero de cal y cemento son palpables lesiones físicas en forma de humedad y suciedad $(66,67 \%)$ y mecánicas en forma de agrietamientos (33,33\%) (Fig. 8).

Si bien los morteros representan un segmento de especial interés por su uso y distribución en los edificios, poco se sabe del origen de sus componentes esenciales. En el caso de la cal se ha documentado su fabricación local a partir de la extracción de caliza de zonas como Lazareto, Baños, Sinincay y otras (Fernández 2018) (Fig. 1), así como en el caso del cemento a partir de hitos productivos como las fábricas Cóndor o Guapán (Delgado Vallejo y Negrete Martínez 2012). Lo cierto es que así como en los materiales previos, la inexistencia de mayores conocimientos técnicos dificulta su comprensión.

Se advierte que la naturaleza de las lesiones, si bien está asociada a factores claramente identificables y cuantificables, proviene del material como origen y catalizador de lesiones. Se trata de un dato esencial para entender el comportamiento de los materiales, aunque la delimitación temporal de las afecciones sufridas es ciertamente compleja (Talaverano et al. 2018) y además, no pasa desapercibido de cara a futuros procesos de intervención, y con ello a la proyección de otros estratos potenciales que conlleven acciones constructivas, destructivas o de restitución.

\section{Coexistencia, lesiones e intervención}

Al continuar con el análisis, la aplicación metodológica y los considerandos de Caballero Zoreda (1995) y Blanco-Rotea (2003) en relación al comportamiento patológico, deja entrever que las acciones constructivas o transformadoras asociadas a los principios de superposición, sucesión y continuidad, la horizontalidad original y continuidad lateral y la relación de cruce o corte evidencian comportamientos dispares, según la ubicación del material y su exposición al medio. Los resultados generales muestran que las mayores afecciones están dadas por ejercicios de intervención, es decir, acciones posteriores concretadas a través de múltiples modalidades (Figs. 5, 6, 7 y 8). Particularmente, la relación de cruce o corte tiende a exponer segmentos de mayor vulnerabilidad a las lesiones, sobre todo en presencia de morteros simples y mixtos. Las juntas constructivas, significativas para comprender el proceso histórico, acentúan esta condición propia de los ejercicios de relleno, reparación, reposición y otras acciones de clara naturaleza posterior (Figs. 9 y 10).

La discontinuidad temporal y los hiatos en el registro estratigráfico asociados a los materiales incrementan la generación de lesiones patológicas debido al tipo de material. No se ha identificado un patrón, pero el análisis diacrónico y sincrónico particular de algún material podría ofrecerlo. Al hablar de la identidad tipológica o persistencia de las facies, debido al uso sostenido de materiales pétreos y ladrillos principalmente, no necesariamente incluye acciones constructivas, incluso con aparejos iguales, que podrían no ser coetáneas (Fig. 11). La inexistencia de estudios particulares sobre el uso de aparejos en momentos históricos específicos acentúa la incertidumbre. Por su parte, la variación en el comportamiento de los materiales puede verse afectada por el tiempo de exposición al medio, a través de su envejecimiento superficial, por el incremento de la suciedad por depósito, la formación de costras e incluso su valoración como pátina.

No se evidencia accionar vinculado al segmento $D e$ los fragmentos incluidos, como variable de intervención, tampoco de incidencia en la generación de lesiones, sin que eso represente su exclusión para el estudio de otras entidades arquitectónicas de mayor data o envergadura, como el caso de la Catedral de la Inmaculada. Por su lado, 1 a interdependencia de acciones y actividades ratifican usos de los mismos materiales locales, tanto en anterioridad, contemporaneidad como posterioridad; su nivel de incidencia formal es variable, al igual que su capacidad de reacción a materiales introducidos, lo cual da cuenta de la diversidad de su composición, calidad y origen. Las acciones anteriores y coetáneas atestiguan situaciones de menor vulnerabilidad (Figs. 6, 7 y 8). $\mathrm{Y}$, sobre el actualismo y uniformismo, el análisis estratigráfico incluye procesos patológicos y tratamientos como parte de la adaptación de la entidad a los diversos tiempos históricos, los cuales se constituyen tanto en acciones constructivas como destructivas. Ambos, al limitar el estudio a la fachada, pudieron confundirse en el análisis. Aun así la aproximación histórico-constructiva 

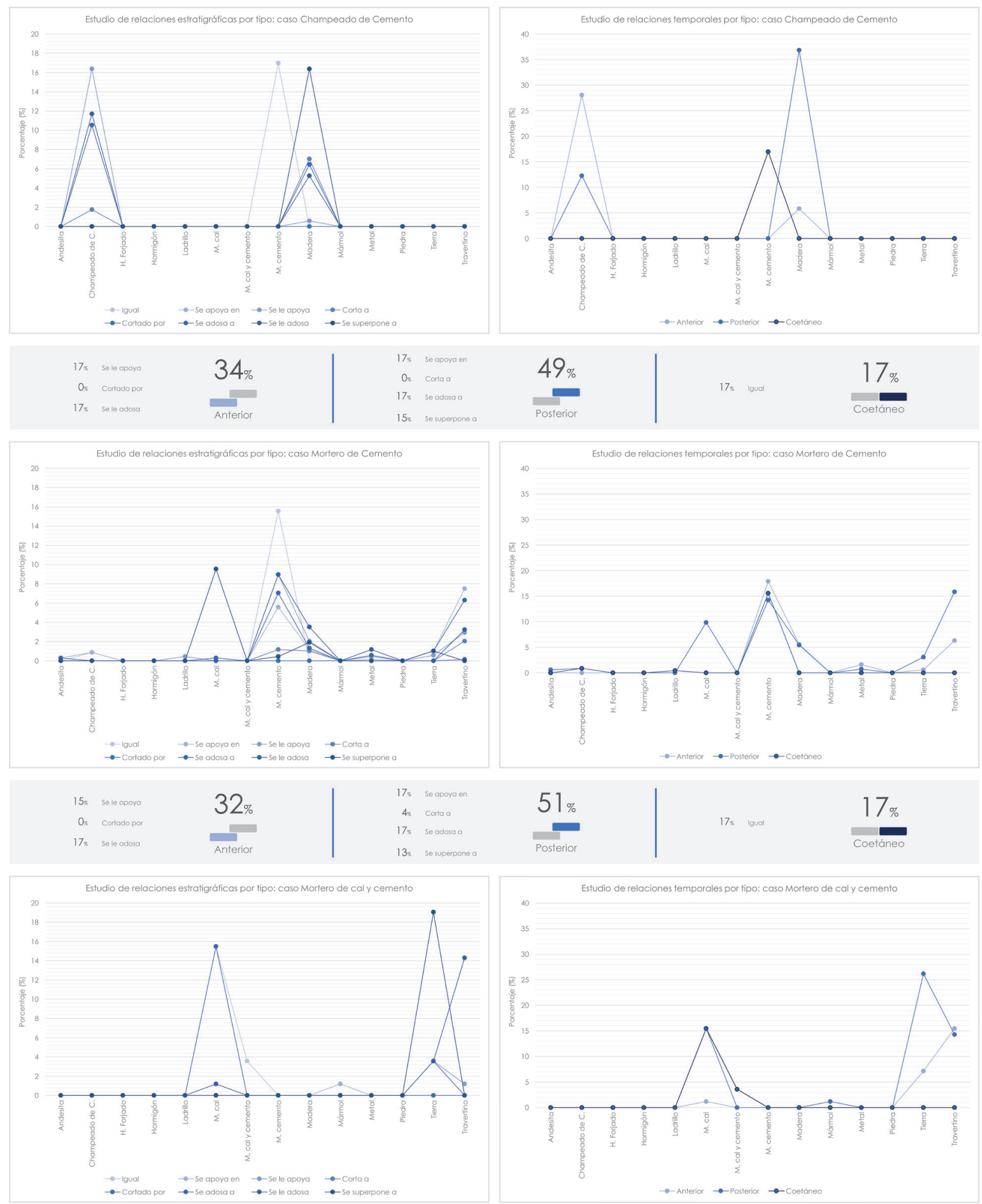
$\begin{array}{ll}55 & \text { Sele apoya } \\ 0.5 & \text { Cortado por }\end{array}$
$24 \%$
$\begin{array}{ll}198 & \text { se apoya } \\ 0.8 & \text { cota } a\end{array}$
19\% sele adosio
Anterior
19. Se odosa a
$\frac{57 \%}{\text { Posterior }}$
19\%

Figura 8. Relación estratigráfica y temporal de champeado de cemento, mortero de cemento y mortero de cal y cemento. Elaboración: Gema Mariela Zamora 2019 


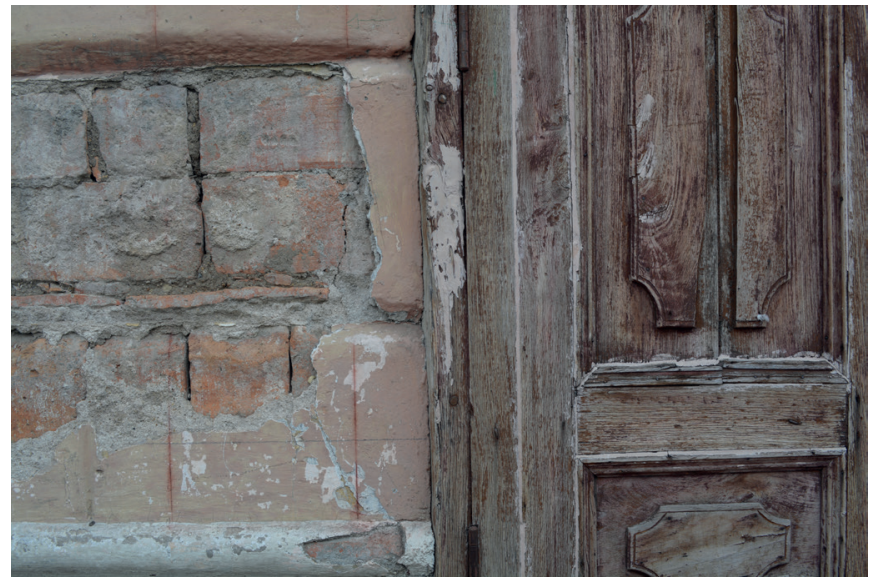

Figura 9. Acciones constructivas / destructivas en el centro histórico de Cuenca. Elaboración: María del Cisne Aguirre Ullauri 2019.

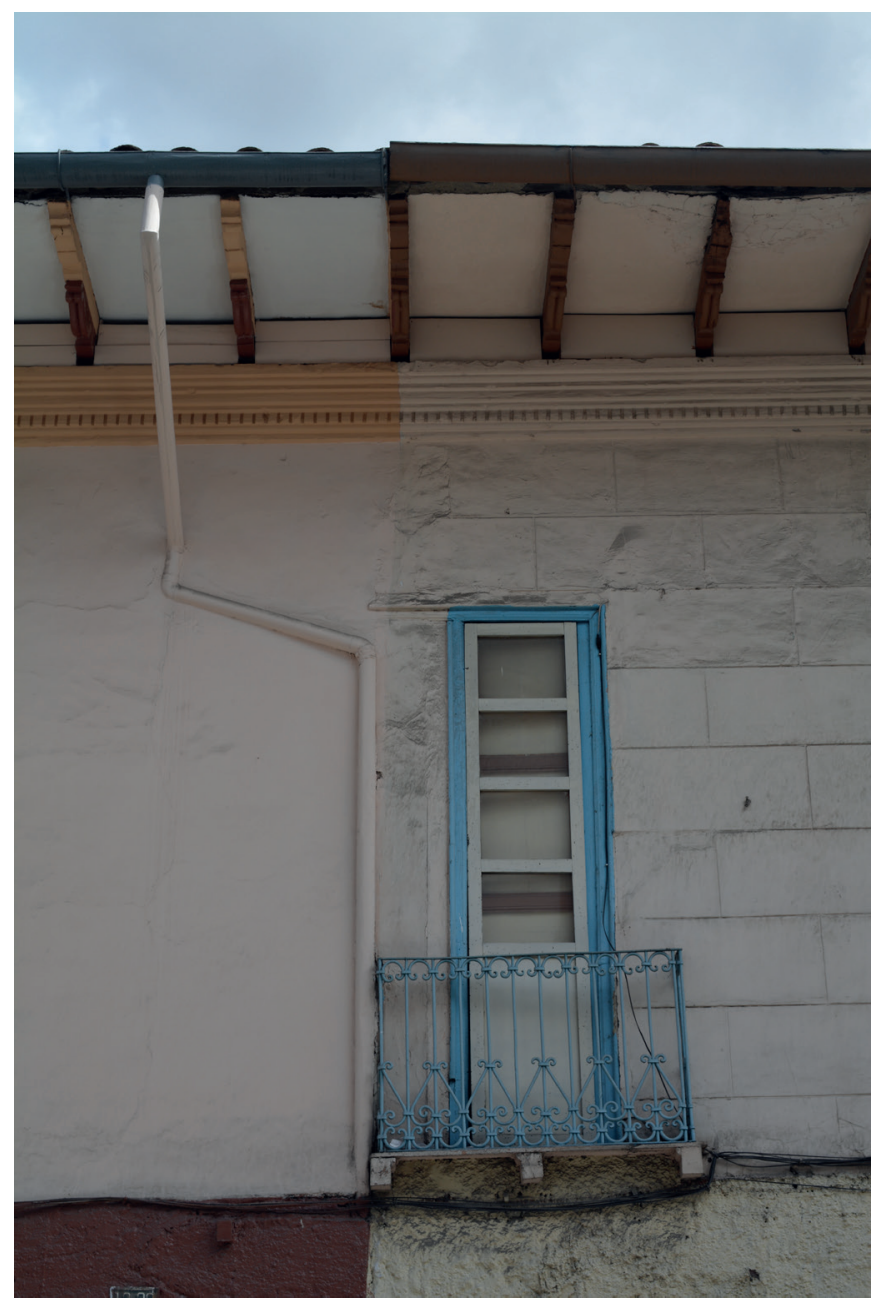

Figura 10. Posible hiato o discontinuidad temporal en el centro histórico de Cuenca. Elaboración: María del Cisne Aguirre Ullauri 2019.

amplía la perspectiva del dictamen patológico como mero reporte de incidencias, a la interacción de dimensiones coexistentes.

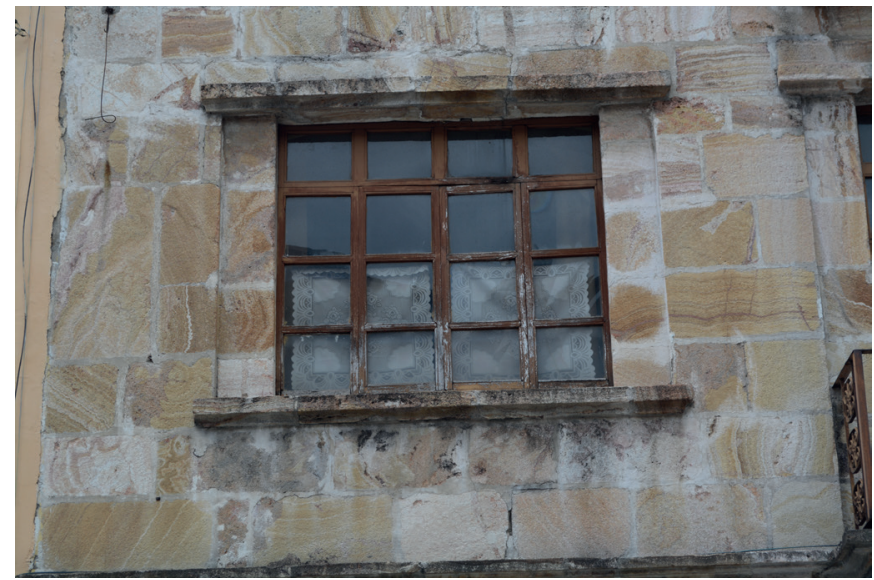

Figura 11. Diferentes aparejos en fachada pétrea. Elaboración: María del Cisne Aguirre Ullauri 2019.

Frente al panorama descrito, las relaciones y comportamientos patológicos identificados han permitido una aproximación a la interacción entre materiales y han evidenciado que tiene un carácter limitado, por lo que es necesario entender la integralidad de su naturaleza para ampliar el espectro de las variables que motivan las afecciones detectadas. Así mismo, se cree importante vincular al proceso, incluso con carácter retrospectivo, la documentación y fuentes de estudios como las provenientes del Archivo Fotográfico del Instituto Nacional de Patrimonio Cultural, o los fondos del Archivo Nacional de Historia, Núcleo del Azuay, con la finalidad de ampliar el estudio desde el ámbito arquitectónico y urbano hacia la dimensión del paisaje urbano histórico y el abordaje integral de su incidencia en la interacción ambiente-materiales, e incluir posibles huellas no detectadas o identificar las denominadas unidades recuperadas (Murillo Fraguero y Utrero Agudo 2004). Bien es sabido que repositorios más allá de los enunciados son inexistentes, aun así la investigación constituye una empresa compleja y de larga duración para las disciplinas dedicadas al estudio y gestión del patrimonio, como la propia arqueología, la arqueometría, la restauración o la arquitectura (Blanco-Rotea 2017).

Desde el segmento de los procesos de intervención existentes y esbozados como producto del análisis desarrollado, queda patente que la definición de estrategias generalizables, aunque agilita la gestión administrativa, limita la conservación del potencial individual y rasgos singulares de los inmuebles (Fig. 12), aún más en el contexto del centro histórico de Cuenca, ya que la gran mayoría de ellos calza en la denominación de arquitectura menor o bienes de valor ambiental. De esta forma, el apostar por la diversidad de fuentes y estrategias de 


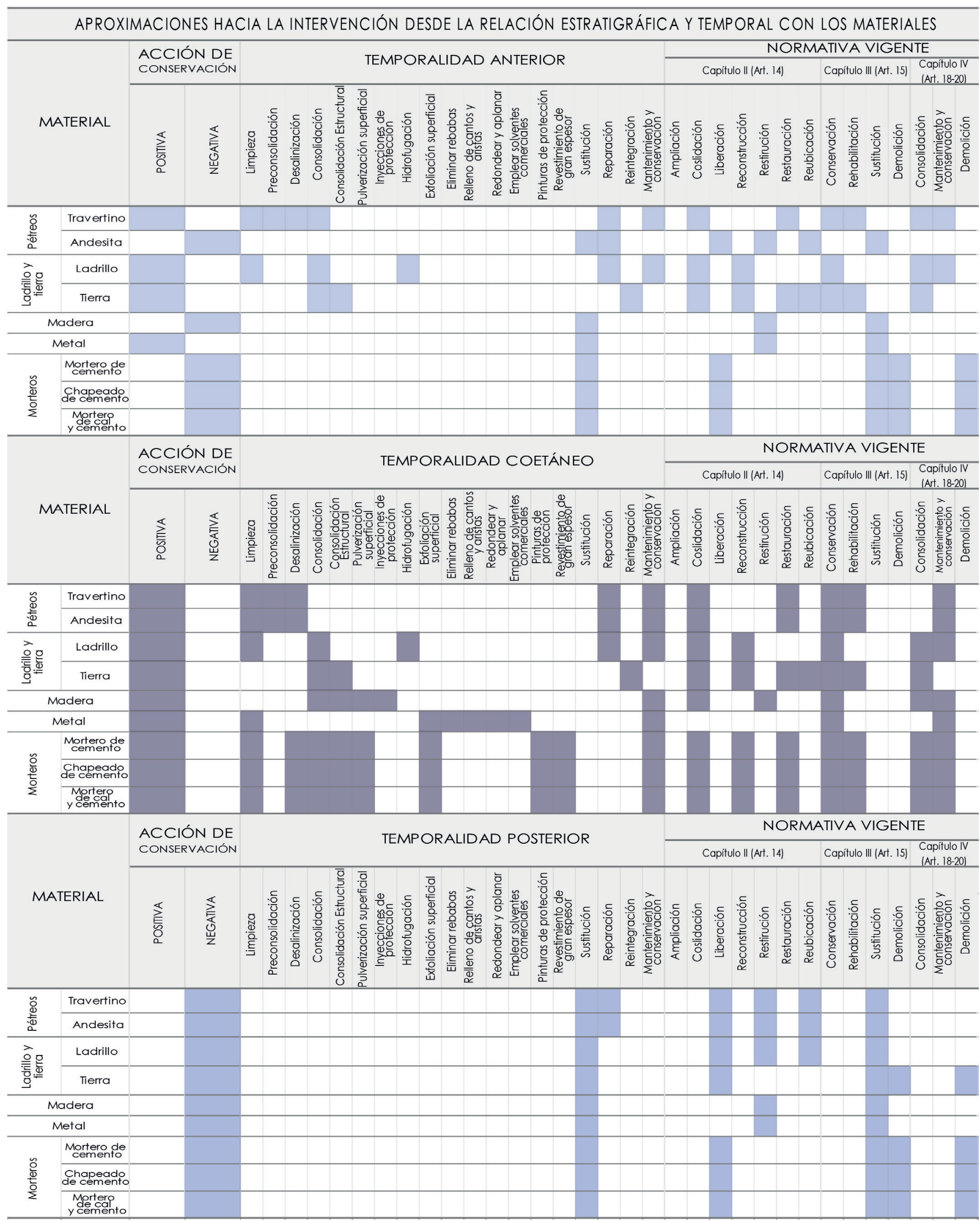

Figura 12. Aproximaciones hacia la intervención desde la relación estratigráfica y temporal con los materiales. Elaboración: Amaranta Andreina Cortés 2019. 
conocimiento y estudio, así como por la complejidad del proceso de conservación patrimonial, constituye un verdadero reto porque implica conocer y aplicar las herramientas arqueológicas como recurso del futuro (Azkarate Garai-Olaun 2013).

En este sentido, con base en la propuesta de Blanco-Rotea (2017) para la aplicación de los parámetros de irrepetibilidad y propiedad compartida, se definen estrategias concretas de acción en el sitio considerando tanto los segmentos temporales asociados al método de estudio aplicado como los parámetros de accionamiento de la Ordenanza para la Gestión y Conservación de las áreas Históricas y Patrimoniales del Cantón Cuenca, desde las categorías definidas en los Capítulos II, III y IV (Fig. 12). En el caso de los materiales coetáneos, la propuesta de conservación es afirmativa: no representan riesgo visible o potencial al daño físico y al detrimento estético y, por tanto, tampoco se halla vulnerabilidad al estado de conservación, por ello las actuaciones se orientan a detener incidencias para asegurar la permanencia del bien patrimonial, entre las recomendadas están la limpieza, consolidación, restauración y mantenimiento. La coexistencia de materiales de temporalidad anterior y posterior es relevante para la generación de lesiones, la posterior es el periodo más incidente debido a que los materiales, incluso siendo los mismos de las otras temporalidades, responden a la condición de agregados no compatibles a nivel físico y, por extensión, a nivel mecánico, químico y biológico. La conservación en este caso es negativa, y se recomienda la sustitución de elementos por otros que sean congruentes como resultado del análisis previo y la planificación de la intervención.

Así mismo, según el artículo 15 de la normativa vigente, es preciso que el tipo de intervención proyectada se ajuste a la categoría del bien y el entorno que lo rodea; al respecto, las edificaciones de Valor Emergente y de Valor Arquitectónico A serán susceptibles únicamente de conservación y restauración, mientras que las edificaciones de Valor Arquitectónico B y de Valor Ambiental, podrán serlo de conservación y rehabilitación arquitectónica. Indudablemente estos parámetros obedecen a criterios macro, por lo que las actuaciones concretas en materiales no necesariamente se corresponden con dichas categorías, sino que, en su lugar, atienden al comportamiento e interacción de los materiales, de tal suerte que toda intervención, al margen de su incidencia, pasa a formar parte de una nueva etapa de la memoria del espacio construido y con ello a ser parte fundamental del proceso de revalorización del patrimonio (Blanco-Rotea 2017). Conviene acotar que actuaciones de simulación de materiales (marmoleado, ladrillo, piedra y otras), aun cuando existan antecedentes en la edificación (Art. 4 del Reglamento de uso del color y materiales en las edificaciones del Centro Histórico), deberán sopesarse concienzudamente. Lo mismo se pide para el cada vez más frecuente ejercicio de despellejar las fachadas (Berriochoa 2008), práctica que propicia vulnerabilidad de materiales.

Adicionalmente, por los casos estudiados y los recursos derivados del diagrama estratigráfico se observa que la evolución histórico-constructiva de los materiales en su nivel conceptual más elemental se enmarca dentro de lo que señalan las referencias historiográficas convencionales. La Matriz de Harris, sin que este haya sido el punto de partida, ratifica dichas aseveraciones, aunque se echa en falta el contar con la documentación identificada como insumos técnicos. También afecta al estudio y limita la construcción del diagrama la imposibilidad de comprender el proceso asociado a la secuencia de degradación y las dificultades para establecer temporalidades a los comportamientos patológicos que la constituyen. En este aspecto, la evaluación de impacto ambiental sobre los materiales a través de los niveles aplicados (Figs. 2 y 12) permite programar prioridades.

\section{El ecosistema y los ambientes de la ciudad histórica}

Bajo la perspectiva material descrita, la sucesión de actividades constructivas y destructivas ratifica la condición de producto manufacturado de la arquitectura histórica (Talaverano et al. 2018), lo que en el caso del centro histórico de Cuenca remarca la autodenominación arquitectónica local, y germina el paso de la cultura material a la inmaterial. La Matriz de Harris (Figs. 13 y 14) ilustra cómo ciertas prácticas convencionales de la sociedad local se asocian de valores específicos determinantes de la condición constructiva o destructiva de un material (Fig. 9). En este sentido, es factible considerar que, si bien la secuencia de degradación (Brogiolo y Cagnana, citado en Brogiolo 2008) describe el detrimento del estado de conservación y prestaciones físico-estructurales, el imaginario colectivo puede reflejar escenarios de apropiación mediante materiales claramente incompatibles.

Esta realidad de la memoria histórica ciudadana, configurada por hitos simbólicos como la Declaratoria de Patrimonio Mundial, invita a hablar del centro 


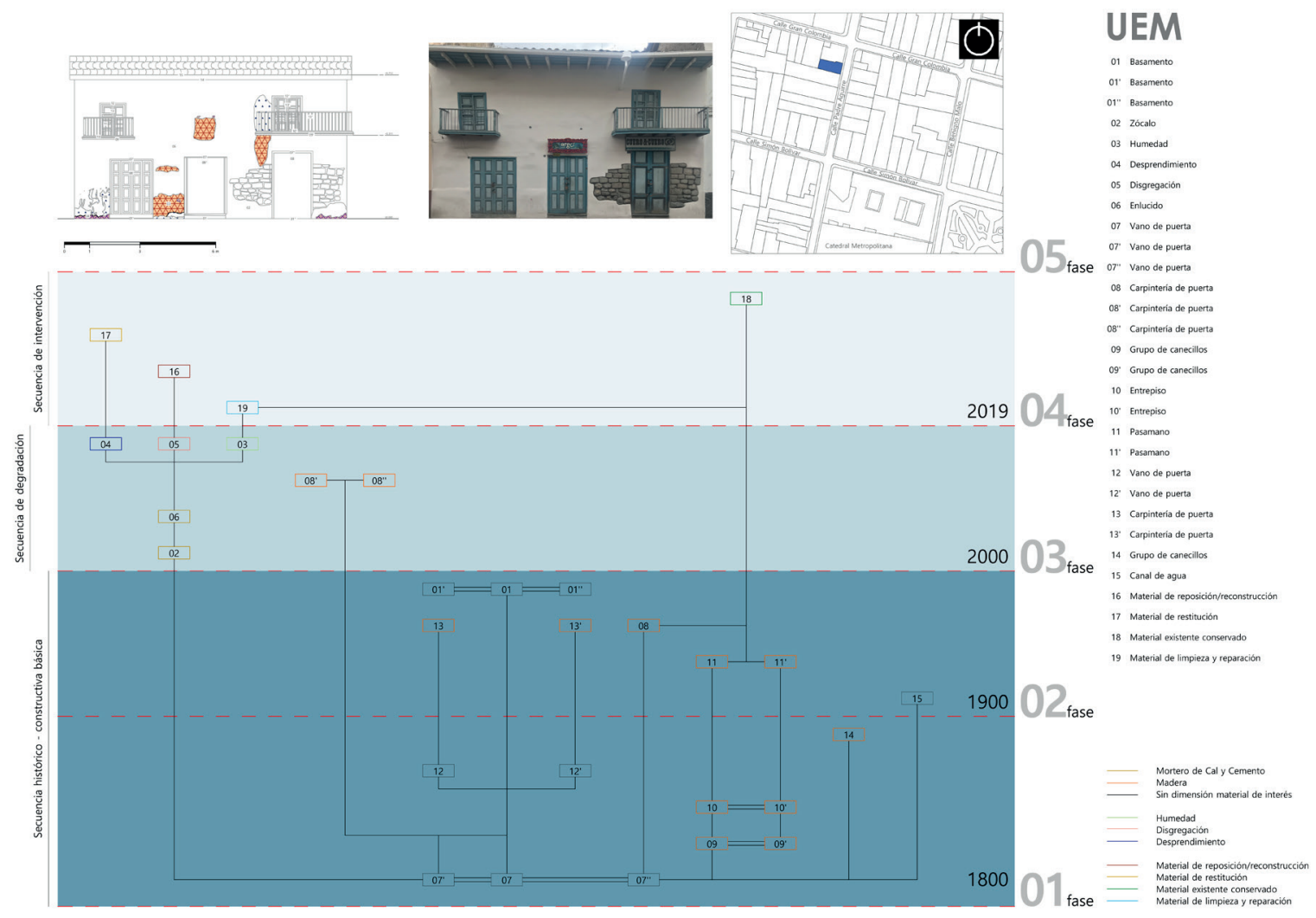

Caso 1: CPAO2 CVA

Casa Villavicencio Aguirre

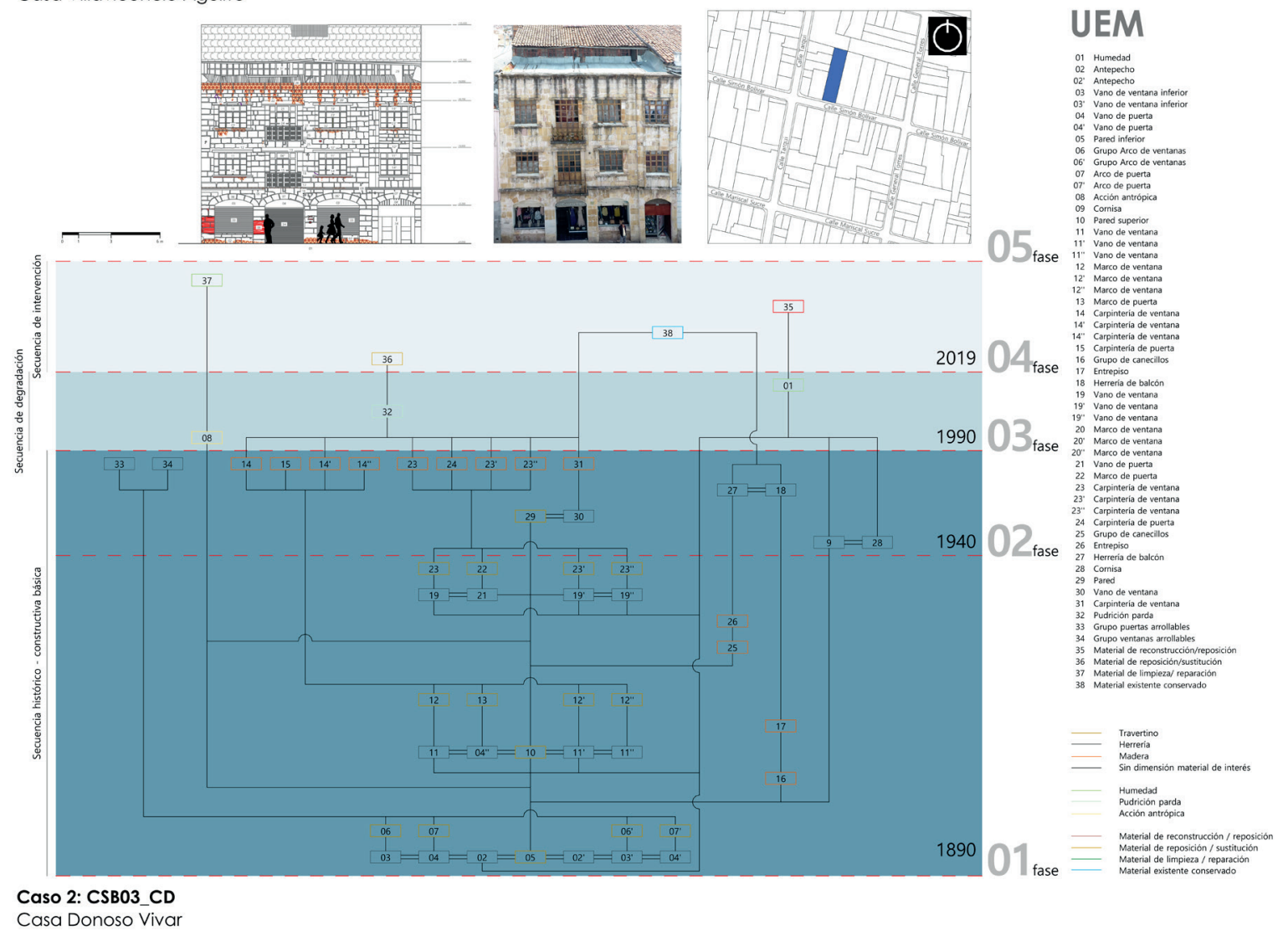

Figura 13. Secuencia histórico-constructiva, de degradación e intervención a través de la Matriz de Harris. Casos 1 y 2. Elaboración: Amaranta Andreina Cortés, Gema Mariela Zamora y María del Cisne Aguirre Ullauri 2019. 


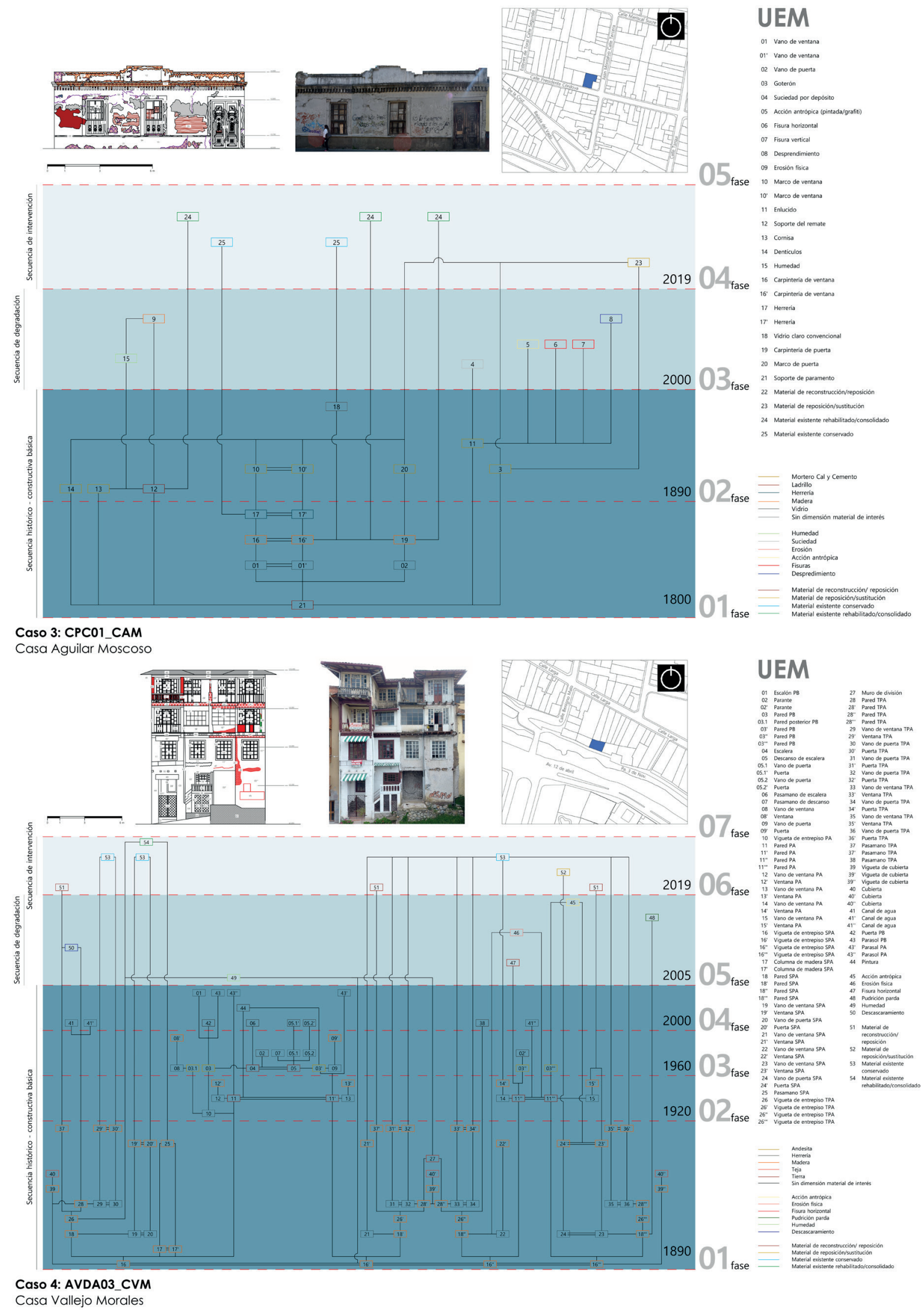

Figura 14. Secuencia histórico-constructiva, de degradación e intervención a través de la Matriz de Harris. Casos 3 y 4 . Elaboración: Amaranta Andreina Cortés, Gema Mariela Zamora y María del Cisne Aguirre Ullauri 2019. 
histórico no como un solo ecosistema, sino varios, que se han construido, renovado, articulado y desarticulado conforme el devenir del tiempo; es decir, hablar de una sumatoria progresiva y un proceso de acumulación de venturas y desventuras (Roch, 2000). El centro histórico de Cuenca, por tanto, no es más que el espejo histórico de la interacción del medio y sus habitantes (Cruz Petit 2014); al tiempo que los motiva, representa y define como individuos; al conducir esa interacción sui géneris desata la crisis de la permanencia, el bienestar, el legado generacional plasmado en las dimensiones materiales de la ciudad y del paisaje social (Ayán Vila 2003).

Los datos sincrónicos y diacrónicos obtenidos han dado lugar a la construcción de la secuencia históricoconstructiva y secuencia de la degradación, que a su vez ayudan a prever una potencial secuencia de intervención y participación/reacción social; es decir, configurar al menos un nuevo estrato (Fig. 10) capaz de aglutinar de manera premeditada actividades tecnificadas y eficaces concretas, de tal suerte que enlazan espacio y tiempo. Por su relación con el diagrama estratigráfico (Figs. 13 y 14), la articulación entre los estratos de la secuencia de degradación y de intervención representa un escenario propicio para la discusión sobre medios técnicos y constructivos, ya sea que evidencie presencia o ausencia, de forma que se represente la conexión materialdegradación-intervención y se eviten confusiones. Sin llegar a ser determinantes, estos procesos estudiados se definen como activos e incluso progresivos, por tanto permanentes. Con esta visión, se apoya al cumplimiento del objetivo de este estudio: emplear el diagnóstico patológico transversal con base en la lectura estratigráfica en la aplicación instrumental e interdisciplinar, y se enmarca en la visión del monitoreo de los componentes de impacto ambiental, patológico e histórico constructivo.

La construcción de las secuencias históricoconstructiva y de degradación proyecta la definición potencial de al menos una tercera, la secuencia de intervención. Al incidir en términos temporales predecibles y con acciones específicas, se contextualiza uno o varios estratos, en los cuales están contenidos procesos activos y activos progresivos de actuación, en correspondencia con la condición patológica particular de los materiales (Figs. 8, 6, 7 y 8). De esta manera es posible definir qué acciones de intervención son prioritarias según la denominada Escala de evaluación de desempeño propuesta por Rodrigues, Teixeira y Cardoso (2011), reconocer los niveles de evaluación de Impacto Ambiental a través de la Matriz de Leopold (Fig. 2) y los indicadores de la escala de Tratamientos de The ABC Method (ICCROM 2016), así como tratar otros insumos técnicos conforme su relación lógica y complementaria con los determinantes de normativa local (Fig. 12). Como observaciones particulares se detecta que los niveles de ampliación y reubicación son mínimamente compatibles por lo que, para el caso de intervención en materiales, su aplicación ha sido excluida (Fig. 15).

No se desconoce que el estudio independiente de la fachada supone solo el inicio de otro más efectivo sobre la realidad histórico-constructiva, supone ruta que abre nuevos caminos. El tema exige estudios a nivel morfológico, estructural y de sintaxis espacial para atender las múltiples problemáticas disciplinares en torno al patrimonio arquitectónico y su interacción con el ecosistema, que podrán conducir a la producción de conocimiento de mayor alcance y a practicar una gestión integral (Fig. 15).

\section{IDEAS FINALES}

Como instrumento de análisis, el ejercicio estratigráfico no solo ha cumplido su rol técnico y ha aportado como método instrumental. Además, ha permitido entender y

\begin{tabular}{|c|c|c|c|c|c|c|c|c|c|c|c|c|c|c|c|}
\hline \multicolumn{4}{|c|}{ EVALUACIÓN } & \multicolumn{12}{|c|}{ TRATAMIENTO } \\
\hline \multirow{2}{*}{\multicolumn{2}{|c|}{$\begin{array}{c}\text { Ambiental } \\
\text { (Matiz de Leopold) }\end{array}$}} & \multirow{2}{*}{\multicolumn{2}{|c|}{$\begin{array}{l}\text { De desempeño } \\
(D L+E I)\end{array}$}} & \multirow{2}{*}{\multicolumn{3}{|c|}{$\begin{array}{l}\text { Ordenanza para la Gestión y Conservación de } \\
\text { las Áreas Históricas y Patrimoniales }\end{array}$}} & \multirow{5}{*}{$\begin{array}{c}\text { De desempeño } \\
\text { (DL + El) } \\
\text { Demolición- } \\
\text { Sustitución } \\
\text { Rehabilitación } \\
\text { mayor }\end{array}$} & \multirow{2}{*}{\multicolumn{3}{|c|}{$A B C$ Method }} & \multirow{2}{*}{\multicolumn{5}{|c|}{ Norma ISO 31000 (2011) }} \\
\hline & & & & & & & & & & & & & & & \\
\hline \multirow{3}{*}{ Crítico } & \multirow{3}{*}{$75-100$} & \multirow{3}{*}{ Insatisfactorio } & & Restitución & \multirow{3}{*}{\multicolumn{2}{|c|}{ Demalición }} & & \multirow{3}{*}{ Recuperar } & \multirow{3}{*}{5} & \multirow{5}{*}{$\begin{array}{l}\text { No } \\
\text { tolerable }\end{array}$} & \multirow{3}{*}{\multicolumn{4}{|c|}{ Acciones emergentes }} & \multirow{5}{*}{$\begin{array}{l}\text { No } \\
\text { tolerable }\end{array}$} \\
\hline & & & 3 & Reconstrucción & & & & & & & & & & & \\
\hline & & & 4 & Restauración & & & & & & & & & & & \\
\hline Severo & $50-75$ & $\begin{array}{l}\text { Parcialmente } \\
\text { Satisfactorio }\end{array}$ & 5 & Liberación & Sustitución & \multirow{2}{*}{ Consolidación } & \multirow{2}{*}{$\begin{array}{l}\text { Acciones de } \\
\text { rehabilitación }\end{array}$} & Responder & 4 & & \multirow{4}{*}{$\begin{array}{l}\text { Acciones } \\
\text { programadas }\end{array}$} & $\begin{array}{l}\text { Corto } \\
\text { plazo }\end{array}$ & \multirow{3}{*}{$\begin{array}{l}\text { Acciones } \\
\text { preliminares }\end{array}$} & \multirow{4}{*}{$\begin{array}{l}\text { Acciones } \\
\text { frente al } \\
\text { riesgo } \\
\text { residual }\end{array}$} & \\
\hline Moderado & $25-50$ & Satisfactorio & $\begin{array}{l}6 \\
7\end{array}$ & Renablita & ción & & & Detectar & 3 & & & Mediano & & & \\
\hline \multirow[t]{2}{*}{ Irrelevante } & \multirow[t]{2}{*}{$0-25$} & Muy satisfactorio & 8 & & Mantenimiento & & $\begin{array}{l}\text { Limpieza y } \\
\text { mantenimiento }\end{array}$ & Bloquear & 2 & \multirow[t]{2}{*}{ Tolerable } & & plazo & & & \multirow[t]{2}{*}{ Tolerable } \\
\hline & & $\begin{array}{l}\text { Completamente } \\
\text { Satisfactorio }\end{array}$ & $\begin{array}{c}9 \\
10\end{array}$ & & Conservación & & $\begin{array}{l}\text { Plan de } \\
\text { mantenimiento }\end{array}$ & Evitar & 1 & & & & plazo & & \\
\hline
\end{tabular}

Figura 15. Articulación de acciones de intervención a la esfera internacional. Elaboración: María del Cisne Aguirre Ullauri 2019. 
generar conocimiento desde otra manera, en la medida en que sobrepasa las tendencias convencionales de ver, entender, explorar y repensar la arquitectura local desde la interpretación estilística o espacio funcional, pues conlleva observaciones sobre las características del documento arquitectónico, sus interacciones con el medio y la descripción de las necesidades del bien. Bajo esta premisa, la evaluación de la interacción entre materiales históricos, factores ambientales y factores antrópicos no refleja solo el estado físico de las estructuras arquitectónicas y la situación urbana, sino que avanza a contextualizar la ocupación, trabajo y hábitat del grupo poblacional del centro histórico de Cuenca. Ciertamente, al interrelacionar los comportamientos vistos en los casos de estudio, se puede efectuar una proyección o interpretación sobre los actores que concibieron, transformaron y habitaron un bien y la influencia de la cambiante situación histórica de la urbe. Con esta relación es posible asociar los factores de incidencia en el registro arqueológico murario en la medida en la que trastocan el ritmo y las huellas de la interacción, en el peor escenario, como un proceso de pérdida de integridad material, pero ante todo de sentido de la arquitectura.

El desarrollo de este trabajo, en esencia, ha facultado conocer los materiales significativos empleados a lo largo de la tradición histórica de la arquitectura y su influencia con el contexto urbano y el paisaje desde la lectura de interacciones físicas y temporales en el edificio. En segundo lugar y por inferencia, ha contribuido a dar cuenta de las falencias a la hora de intervenir en el centro histórico. A su vez, el tema tratado se ha justificado por el progresivo interés por la conservación y la actuación en las estructuras patrimoniales del centro histórico de Cuenca, atención que evidenció que el segmento de las lesiones patológicas, su comportamiento, tratamiento y los mecanismos asociados a su comprensión, entre ellos el estudio de la calidad de materiales existentes y materiales sensibles a utilizarse, representa un escenario de desarrollo vital que, de la mano de una mayor conciencia técnica patrimonial en el eje administración/ academia/comunidad, permitirían la implementación de mejores y más efectivas acciones.

Finalmente, no es menos importante destacar que a lo largo del proceso investigativo no han sido identificados casos, ejemplos o ejercicios singulares de aplicación de los recursos arqueológicos a la arquitectura fuera del contexto instrumental complementario, por lo que el ensayar la aplicación del método se consigue apreciar su versatilidad, así como difundir su valor como técnica que resignifica la importancia del contexto geográfico en la producción arquitectónica. Como recurso analítico, ha superado sus propios convencionalismos, representados en máxime por la Matriz de Harris, propia de la didáctica del registro estratigráfico del patrimonio edificado, y ha optado por el conocimiento desde las leyes estratigráficas para equilibrar los valores socio culturales y la importancia técnica del patrimonio, como recursos para su propia conservación. Así mismo, a partir de la presente investigación, se han agregado nuevos escenarios para la empresa investigativa; el camino recién empieza.

\section{BIBLIOGRAFÍA}

Abad, L. y Tommerbakk, M. 2009. Ciudad y arquitectura republicana de Ecuador: 1850-1950. Facultad de Arquitectura, Diseño y Artes, Pontificia Universidad Católica del Ecuador, Quito, Ecuador.

Achig, M., Zúñiga, M., García, G., Aguirre, A., Galán, N., Barsallo, G. y Briones, J. 2016. Altas de daños. Edificaciones Patrimoniales de Cuenca. Proyecto vlirCPM. Universidad de Cuenca, Cuenca.

Aguirre Ullauri, M., García Cordero, A. y López León, D. 2018. "Los materiales del Centro Histórico de Cuenca: Estado de conservación y representatividad Histórico Constructiva", en Actas del Quinto Congreso Medio Ambiente Construido y Desarrollo Sustentable, pp. 1-12. Universidad Tecnológica José Antonio Echeverría, Cuba.

Aguirre Ullauri, M. y Sanz Arauz, D. 2017. "Caracterización de materiales históricos para el conocimiento y la conservación del Patrimonio Arquitectónico: revisión y proyección en el caso de Cuenca (Ecuador)", en L. Traversa, Actas del V Congreso Iberoamericano y XIII Jornada Técnicas de Restauración y Conservación del Patrimonio. “Dr. Arq. Osvaldo Otero”, pp. 48-64. La Plata.

Aguirre Ullauri, M., Sanz Arauz, D. y Vela Cossío, F. 2018. "Los materiales en la ciudad histórica: identificación, valoración y conservación. El caso de Cuenca, Ecuador", en L. Villega, I. Lombillo, H. Blanco e Y. Boffill, Rehabend 2018. Construction Pathology, Rehabilitantion Technology and Heritage Management Congress, pp. 1339-1348. Cáceres.

Aguirre Ullauri, M., Solano, J., García, A., López, D., Carrión, P., Segarra, C. y Yamunaqué, L. 2018a. "Evaluación del impacto ambiental en la arquitectura patrimonial a través de la aplicación de la Matriz de Leopold como un posible sistema de Monitoreo Interdisciplinar". ASRI. Arte y Sociedad. Revista de Investigación, 14, pp. 17-34.

Aguirre Ullauri, M., Solano Peláez, J., Segarra Villacís, C. y Carrión Cabrera, P. 2018b. "El impacto ambiental sobre los materiales históricos: Evaluación de niveles de incidencia en el caso de Cuenca (Ecuador)", en Actas del Quinto Congreso Medio Ambiente Construido y Desarrollo Sustentable, pp. 1-13. Universidad Tecnológica José Antonio Echeverría, Cuba.

Alulema Pichasaca, R. 2018. La sabiduría cañari de la chacra en relación con la salud y el ambiente, frente a la modernización agropecuaria en la organización Tucayta. Tesis Doctoral en Salud Colectiva, Ambiente y Sociedad. Universidad Andina Simón Bolívar, Sede Ecuador, Quito.

Álvarez Palma, A. M. 2001. "Ciclos productivos y patrón de asentamiento en un sitio Huatabampo, del sur de Sonora", Arqueología, (26), pp. 89-100.

Armenteras, D., González, T. M., Vergara, L. K., Luque, F. J., Rodríguez, N. y Bonilla, M. A. 2016. "Revisión del concepto de ecosistema como "unidad de la naturaleza' 80 años después de su formulación”, Ecosistemas. Revista Cientifica de Ecología y medio ambiente, 25 (1), pp. 83-89. https://doi. org/10.7818/ecos.2016.25-1.12

Ayán Vila, X. 2003. “Arquitectura como tecnología de la construcción de la realidad social”, Arqueología de la Arquitectura, 2, pp. 17-24. https://doi. org/10.3989/arq.arqt.2003.20 
Azkarate Garai-Olaun, A. 2002. "Intereses cognoscitivos y praxis social en arqueología de la arquitectura", Arqueología de la Arquitectura, 1, pp. 5572. https://doi.org/10.3989/arq.arqt.2002.6

Azkarate Garai-Olaun, A. 2013. "La construcción y lo construido. Arqueología de la Arquitectura", en J. A. Quirós (dir.), La materialidad de la historia. La arqueología en los inicios del siglo XXI, pp. 271-198. Akal Editores, Madrid.

Benedet, V. 2012. "La arquitectura colonial de Buenos Aires. Análisis historiográfico, balance crítico y nuevas herramientas para su estudio", Bibliographica Americana, 8, pp. 1-32.

Berriochoa, V. 2008. "Despellejar las fachadas", Revista internacional del patrimonio histórico, 1, pp. 26-28.

Blanco Rotea, R. 2003. "Arquitectura como construcción estratificada". Arqueología de la Arquitectura, 2, pp. 55-62. https://doi.org/10.3989/arq. arqt.2003.24

Blanco-Rotea, R. 2017. "Arquitectura y paisaje. Aproximaciones desde la arqueología”, Arqueología de la Arquitectura, 14, pp. 1-49. http://doi. org/10.3989/arq.arqt.2017.007

Brogiolo, G. 2008. "Procedure di documentazione e processi intepretativi dell'edifilizia storia alla luce delle 'Linee Guida per la valutazione e riduzione del rischio sísmico del Patrimonio Culturale", Archaeologia dell"architettura, XII, pp. 9-13.

Caballero Zoreda, L. 1995. "Método para el análisis estratigráfico de construcciones históricas o "Lectura de Paramentos", Informes de la Construcción, 46 (435), pp. 37-46. https://doi.org/10.3989/ic.1995.v46.i435.1096

Caballero Zoreda, L. 2002. "Sobre límites y posibilidades de la investigación arqueológica de la arquitectura. De la estratigrafía a un modelo histórico", Arqueología de Arquitectura, 1, pp. 83-100. https://doi.org/10.3989/arq. arqt.2002.8

Caldas, V. y Sigcha, P. 2017. Breve análisis cronológico de la introducción de materiales relevantes dentro de las edificaciones del Centro Histórico de Cuenca entre los años 1880 y 1980. Tesis de pregrado, Facultad de Arquitectura y Urbanismo, Universidad de Cuenca, Cuenca.

Cardoso, F. 2012. Metodología de Manuales de Conservación Preventiva. Proyecto vlirCPM. Universidad de Cuenca, Cuenca.

Cardoso, F. 2017. Propuesta para la inscripción del Centro Histórico de Cuenca, Ecuador en la lista de patrimonio Mundial. Edición Comentada 2017. Universidad de Cuenca, Cuenca.

Consulplan. 1982. Plan de desarrollo urbano del área metropolitana de la Ciudad de Cuenca. Vol. XII: Diagnóstico - Centro Histórico, Cuenca, Ecuador, pp. 49-69.

Cruz Petit, B. 2014. "Las relaciones entre sociedad, espacio y medio ambiente en distintas conceptualizaciones de la ciudad", Estudios Demográficos y Urbanos, 29 (85), pp. 183-205. https://doi.org/10.24201/edu.v29i1.1459

De Jongh, S., Van Wijnendaele, M., Cardoso, F. y Van Balen, K. 2009. Damage Atlas of historical Cuenca-Ecuador. Damage patterns found /mainly earthen) building materials. Katholieke Universiteit, Leuven.

Delgado Vallejo, A. E. y Negrete Martínez, C. A. 2012. Evaluación de uso de arcillas y puzolanas en la etapa de molienda de acabado para la fabricación de cemento portland puzolánico tipo IP. Tesis de pregrado. Universidad de Cuenca, Cuenca. http://dspace.ucuenca.edu.ec/ bitstream/123456789/2389/1/tq864.pdf

Espinoza, P. y Calle, I. 2002. La cité cuencana: el afrancesamiento de Cuenca en la época republicana (1860-1940). Serie de Cuenca No. 1, Facultad de Arquitectura y Urbanismo, Universidad de Cuenca, Cuenca.

Fernández, D. 2018. Recuperación de saberes andinos: Documentación del proceso de elaboración artesanal de la cal. "Lazareto, Azuay". Tesis de pregrado. Universidad Católica de Cuenca, Cuenca.

Fernández-Galiano, L. 1991. El fuego y la memoria. Sobre arquitectura y energía. Alianza, Madrid.

Fortea Luna, M. y Garcés Desmaison, M. 2011. "Historia de la Construcción y Arqueología: el análisis constructivo de la vida del monumento", en S. Huerta, I. Gil Crespo, S. García y M. Taín (eds.), Actas del Séptimo Congreso Nacional de Historia de la Construcción, pp. 415-419. Instituto Juan de Herrera, Madrid.

GAD de Cuenca. 2018. Arquitectura colonial y materiales tradicionales del barrio de San Sebastián. Graf\&Pack, Cuenca.
García Gómez, I. 2009. “Sistemas complejos y arqueología. Una aproximación teórica al fenómeno urbano", Arqueología de la Arquitectura, 6, pp. 63-92. https://doi.org/10.3989/arqarqt.2009.09007

Gómez, P., Medina, M., Andrade, S. y Medina, J. 1986. Crítica arquitectónica de la producción residencial en Cuenca: 1961-1980. Tesis de pregrado, Facultad de Arquitectura y Urbanismo, Universidad de Cuenca, Cuenca.

González, G., Zúñiga, L., Ullauri, C. y Cornejo, F. 1980. Arquitectura civil en Cuenca en la época republicana. Tesis de pregrado, Facultad de Arquitectura y Urbanismo, Universidad de Cuenca, Cuenca.

ICCROM. 2016. The ABC Method: a risk management approach to the preservation of cultural heritage. Canadian Conservation Institute, Canadá.

ICOMOS. 1987. Carta Internacional para la Conservación de Ciudades Históricas y Áreas Urbanas Históricas (Carta de Washington 1987): principios $y$ objetivos. https://www.icomos.org/charters/towns sp.pdf?fbclid=IwAR28VgawWAq0q_TLwDDjLn-iKzw3ALuPgTYNINY vhR8QmNAPunzVk1PtmvA

ICOMOS. 2003. Principios para el Análisis, Conservación y Restauración de las estructuras del Patrimonio Arquitectónico. https://www.icomos.org/ charters/structures_sp.pdf?fbclid

Idrovo, J. 2008. Inventario y catastro de inmuebles y sitios con valor arqueológico localizados en el Centro Histórico de Cuenca. Unidad de Arqueología Urbana. Ilustre Municipio de Cuenca, Cuenca.

Ilustre Concejo Municipal de Cuenca. 2010. Ordenanza para la Gestión y Conservación de las Áreas Históricas y Patrimoniales del Cantón Cuenca. Actualización. Ecuador.

Instituto Geográfico Militar-IGM. 1974. Azogues. Mapa geográfico del Ecuador. Escala 1:50000. Quito.

Jamieson, R. 2003. De Tomebamba a Cuenca. Arquitectura y arqueología colonial. Abya-Yala, Quito.

Jaramillo, D., Salazar, E., Martínez, J., Abad, A. y Aguilar, F. 2004. Cuenca, Santa Ana de las Aguas. Ediciones Libri Mundi, Quito.

León, K., Luna, L. y Sigüencia, M. 1997. Guía arquitectónica de Cuenca. Tesis de pregrado, Facultad de Arquitectura y Urbanismo, Universidad de Cuenca, Cuenca.

Mannoni, T. 2005. "Archeologia della produzione architettonica. Le tecniche costruttive", Arqueología de la Arquitectura, 4, pp. 11-19. https://doi. org/10.3989/arq.arqt.2005.73

Mannoni, T. 2006. “Arqueología, Arqueometría e Historia de la Cultura Material", en R. Carta (coord.), Arqueometría y arqueología medieval, pp. 17-36, Universidad de Génova, Instituto de Historia de la Cultura Material, Génova.

Mercé Gandía, J. y Gallegos Arias, J. 2011. San Francisco. Una historia para el futuro. Tribal, Quito.

Moreno Martín, F. J. 2014. “Arqueología de la Arquitectura. Una visión conciliadora desde la Historia del Arte", Arqueología de la Arquitectura, 11, pp. 1-19. https://doi.org/10.3989/arq.arqt.2014.008

Moyano, G. y Rivera, M. 2002. Arquitectura de líneas rectas: influencia del movimiento moderno en la arquitectura de Cuenca (1950-1965). Tesis de pregrado, Facultad de Arquitectura y Urbanismo, Universidad de Cuenca, Cuenca.

Murillo Fraguero, J. y Utrero Agudo, M. 2004. "Las lagunas estratigráficas y las superficies negativas en arqueología", Arqueología de la Arquitectura, 3, pp. 163-171. https://doi.org/10.3989/arq.arqt.2004.68

Orellana Samaniego, M., Sellers Walden, Ch. y Martínez Gavilánez, J. 2017. "Índice de calidad ambiental urbana de Cuenca", Universidad y Verdad, 73, pp. 66-77.

Pizzo, A. 2009. "La Arqueología de la Construcción. Un laboratorio para el análisis de la arquitectura de época romana", Arqueología de la Arquitectura, 6, pp. 31-45. https://doi.org/10.3989/arqarqt.2009.09001

Quirós Castillo, J. 2002. "Arqueología de la Arquitectura en España", Arqueología de la Arquitectura, 1, pp. 2738. https://doi.org/10.3989/arq. arqt.2002.4

Rivera Blanco, J. y Pérez Arroyo, S. 2000. Carta de Cracovia 2000. Principios para la conservación y restauración del patrimonio construido. Versión española del Instituto Español de Arquitectura (Universidad de Valladolid), Comité Científico de la Conferencia Internacional Cracovia 2000. 
Roch, F. 2000. "El centro histórico en el marco de la sostenibilidad económica y social", en J. Iglesias (ed.). Actas de los XI Cursos Monográficos sobre el Patrimonio Histórico, pp. 391-408. Universidad de Cantabria, Reinosa.

Rodrigues, M., Teixeira, F. y Cardoso, J. 2011. "Building envelope anomalies: A visual survey methodology", Constructions and Building Materials, 25, pp. 2741-2750. https://doi.org/10.1016/j.conbuildmat.2010.12.029

Rodríguez, M. A., Monteagudo, I., Saroza, B., Nolasco, P. y Castro, Y. 2011. "Aproximación a la patología presentada en las construcciones de tierra. Algunas recomendaciones de intervención”, Informes de la construcción, 63, pp. 97-106. https://doi.org/10.3989/ic.09.007

Rolón, G. 2013. La vivienda popular riojana del ámbito rural. Patrones arquitectónicos y contexto social en los valles durante el Período Republicano. Tesis de Doctorado. Universidad de Buenos Aires, Buenos Aires. Talaverano, M., Cámara, L. y Murillo, J. 2018. “Análisis integrado de construcciones históricas: secuencia estratigráfica y diagnóstico patológico.
Aplicación en la iglesia de Santa Clara (Córdoba)", Arqueología de la Arquitectura, 15, pp. 1-29. https://doi.org/10.3989/arq.arqt.2018.001

Taramasso, E. 1943. El travertino. Universidad de Buenos Aires. Facultad de Ciencias Económicas, Buenos Aires.

Vargas Lorenzo, C. 2013. "Reflexiones sobre cronotipologías en Arqueología de la Arquitectura", Arqueología de la Arquitectura, 10, pp. 1-26. https:// doi.org/10.3989/arq.arqt.2013.001

Vásconez D. S. 2000. "Hacia una nueva gestión ambiental urbana", en F. Carrión (ed.), Desarrollo cultural y gestión en centros históricos, pp. $247-$ 256. FLACSO, Ecuador.

Vicente, R., Ferreira, T. M. y Mendes da Silva, J. A. R. 2015. "Supporting urban regeneration and building refurbishment. Strategies for building appraisal and inspection of old building stock in city centers", Journal of Cultural Heritage, 16 (1), pp. 1-14. https://doi.org/10.1016/j. culher.2014.03.004 